\title{
Inflammation, a Link between Obesity and Cardiovascular Disease
}

\author{
Zhaoxia Wang and Tomohiro Nakayama \\ Division of Laboratory Medicine, Department of Pathology and Microbiology, Nihon University School of Medicine, \\ 30-1 Ooyaguchi-kamimachi, Itabashi-ku, Tokyo 173-8610, Japan \\ Correspondence should be addressed to Tomohiro Nakayama, tnakayam@med.nihon-u.ac.jp
}

Received 30 November 2009; Revised 10 March 2010; Accepted 17 June 2010

Academic Editor: Gema Frühbeck

Copyright ( 2010 Z. Wang and T. Nakayama. This is an open access article distributed under the Creative Commons Attribution License, which permits unrestricted use, distribution, and reproduction in any medium, provided the original work is properly cited.

\begin{abstract}
Obesity, the most common nutritional disorder in industrialized countries, is associated with an increased mortality and morbidity of cardiovascular disease (CVD). Obesity is primarily considered to be a disorder of energy balance, and it has recently been suggested that some forms of obesity are associated with chronic low-grade inflammation. The present paper focuses on the current status of our knowledge regarding chronic inflammation, a link between obesity and CVDs, including heart diseases, vascular disease and atherosclerosis. The paper discusses the methods of body fat evaluation in humans, the endocrinology and distribution of adipose tissue in the genders, the pathophysiology of obesity, the relationship among obesity, inflammation, and CVD, and the adipose tissue-derived cytokines known to affect inflammation. Due to space limitations, this paper focuses on Creactive protein, serum amyloid A, leptin, adiponectin, resistin, visfatin, chemerin, omentin, vaspin, apelin, and retinol binding protein 4 as adipokines.
\end{abstract}

\section{Introduction}

Obesity, the most common nutritional disorder in industrialized countries, is associated with an increased mortality and morbidity of cardiovascular disease (CVD) [1]. The World Health Organization estimates that more than 1 billion adults worldwide are overweight, 300 million of whom are clinically obese-defined as having a body mass index (BMI) equal to or greater than $30 \mathrm{~kg} \mathrm{~m}^{-2}$, or a waist circumference greater than $94 \mathrm{~cm}$ for men and $80 \mathrm{~cm}$ for women [2]. Obesity is a chronic, multifactorial, and complex disease resulting from a long-term positive energy balance, in which both genetic and environmental factors are involved $[3,4]$. It was recently suggested that some forms of obesity are associated with chronic low-grade inflammation [5].

CVDs, including heart disease, vascular disease and atherosclerosis, are the most critical global health threat, contributing to more than one-third of the global morbidity. In most cases, these clinical conditions result from atherosclerosis, which was once identified as a lipid-storage disease. At the present time, CVD is recognized as a chronic inflammatory condition of the vessel wall that results from the transendothelial passage (transcytosis) of cholesterolrich atherogenic Apo-B lipoproteins (VLDL, IDL and LDL) from the plasma into the intima. These lipoproteins are retained in the subendothelial space, which leads to infiltration of macrophages and $\mathrm{T}$ cells that ultimately then interact with each other and with the cells of the arterial wall $[6,7]$. It is likely that inflammation induced by obesity accelerates the atherosclerosis. Adipose tissue is recognized as an important player in obesity-mediated CVD. In 1994, adipose tissue was first identified as the source of the hormone leptin, opening the door for a new era of research that focused on adipocyte endocrinology [8]. It is now apparent that adipocytes have a more complex physiological role [9]. Adipocytes produce large numbers of hormones, peptides, and other molecules that affect cardiovascular function, not only in an endocrine manner, but also by autocrine and paracrine mechanisms [10]. This might lead to cytokine-mediated inflammatory, changes in the liver, systemic inflammation and atherosclerosis. 
This paper focuses on the inflammation related to obesity and CVD. It will discuss the methods of body fat evaluation in humans, the endocrinology and distribution of adipose tissue in the genders, the pathophysiology of obesity, the relationship among obesity, inflammation and $\mathrm{CVD}$, and the adipose tissue-derived cytokines known to affect inflammation.

\section{Methods of Evaluation of Body Fat in Humans}

There are many methods that can be used to evaluate body fat in different populations $[2,11,12]$. While anthropometric measurements of weight-for-height have been traditionally used to evaluate obesity, more recently, BMI has become a standard parameter. BMI is defined as weight in kilograms divided by height in square meters. The normal range is $19-24.9 \mathrm{~kg} / \mathrm{m}^{2}$, with overweight defined as $25-$ $29.9 \mathrm{~kg} / \mathrm{m}^{2}$, and obesity as $\geq 30 \mathrm{~kg} / \mathrm{m}^{2}$. BMI is not always a reliable measurement of body composition in individuals, particularly in older and younger people. Unfortunately, BMI does not provide any insight into regional body fat distribution. Thus, simple anthropometric measurements, such as waist circumference, can also be used to determine the valid index of visceral fat accumulation, in addition to being able to serve as an indicator of health risks associated with visceral obesity. A waist circumference of greater than $102 \mathrm{~cm}$ in men and $88 \mathrm{~cm}$ in women is a risk factor for CVD. A particularly important anthropometric parameter that has been increasingly applied in recent years is sagittal abdominal diameter (SAD) [13]. Using a simple caliper that was originally developed by Kahn, this anthropometric indicator can measure visceral fat tissue alone [14].

With regard to other techniques, one of the first that should be considered is the measuring of body density, as this provides information on the relationship between the body mass and volume. With tetrapolar bioelectric impedance analysis, data is obtained by measuring the resistance of the body exposed to the impact of an alternating current of $50 \mathrm{kHz}$ at a strength of $800 \mu \mathrm{A}$. Radioisotopic techniques use deuterium or tritium as markers to measure the total body liquid and total body potassium. Infrared spectrometry is a simple but not particularly reliable method, based on the application of two sources of monochromatic light. Ultrasonographic measuring of fat tissue is currently the favored technique by which one can measure both the subcutaneous and visceral fat tissues. Measurements are carried out using a $7.5-$ and $3.5-\mathrm{mHz}$ transducer for the subcutaneous and visceral fat tissue, respectively. The most accurate method for measuring central obesity is through the use of magnetic resonance imaging or computer-assisted tomographic scanning. Unfortunately, these approaches are too expensive for routine use.

\section{Endocrinology and Distribution of Adipose Tissue between Genders}

It is now apparent that adipose tissue is not simply a storage reservoir of fat, but is an active endocrine

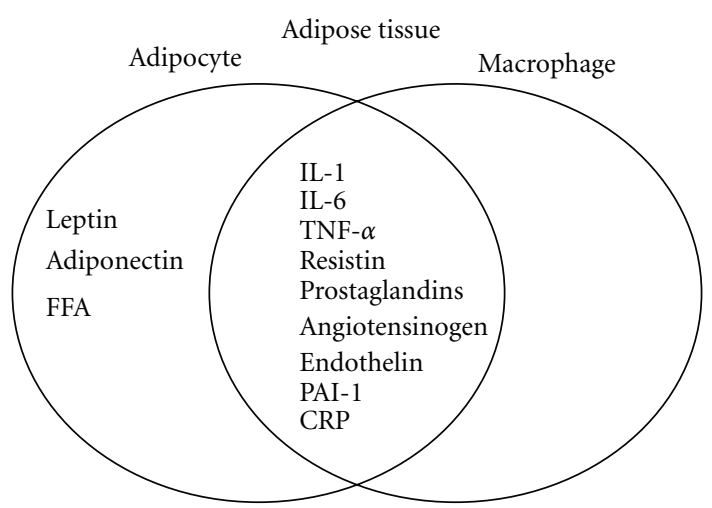

FIGURE 1: Cytokines secreted by adipocytes and/or macrophages in human adipose tissue.

organ that plays multiple roles in the body. Adipose tissue contributes to the inflammatory process in obese subjects in both vascular and nonvascular tissues [15]. Abnormal levels of metabolites, such as lipids, fatty acids and, cytokines from adipose tissue, activate monocytes and increase the secretion of inflammatory cytokines. Adipose tissue from obese individuals contains activated macrophages that together with adipocytes produce various cytokines (Figure 1). These include inflammation-related adipokines such as leptin, adiponectin, tumor necrosis factor alpha (TNF- $\alpha$ ), interleukin-1 (IL-1), interleukin-6 (IL-6), procoagulant substances such as PAI-1, vasoactive substances such as leptin, angiotensinogen and endothelin, and molecules that may contribute to insulin resistance such FFA, TNF- $\alpha$ and resistin. IL-1 signaling involves the type I Interleukin 1 receptor (IL-1R/IL-1R1), a Toll-like receptor that heterodimerizes with the IL-1R accessory protein (IL-1RAcP). Interleukin 1 receptor antagonist (IL$1 \mathrm{Ra})$ is an anti-inflammatory cytokine that binds to IL$1 \mathrm{R}$ in competition with the proinflammatory cytokine IL1. The relative occupancy of the IL-1R1-IL-1RAcP receptor complex with IL-1 agonist or with IL-1Ra determines whether the inflammatory signaling is "on" or "silenced", respectively. IL-1 $\beta$ induction of IL- 6 and prostaglandin E2 (PGE2) signaling is indicated in Figure 3. In obesity, these cytokines are released into the circulation by adipose tissue, stimulating hepatic CRP production. Levels of the prothrombotic molecule PAI-1 are also increased, whereas adiponectin, which is produced exclusively by adipocytes, is decreased in obesity. One of the key vasoactive substances produced by adipocytes is leptin, which is an important regulator of food intake. Other adipocyte-derived molecules, including prostaglandins, adiponectin, and the more recently discovered resistin, affect metabolic function and might play a role in causing cardiovascular end-organ damage.

Serum adipokine levels are elevated in humans and animals with excess adiposity. Visceral fat appears to produce several adipokines more actively than subcutaneous adipose tissue, and an increased abdominal adiposity in the visceral depot renders these individuals more prone to metabolic and cardiovascular problems [16]. Health 


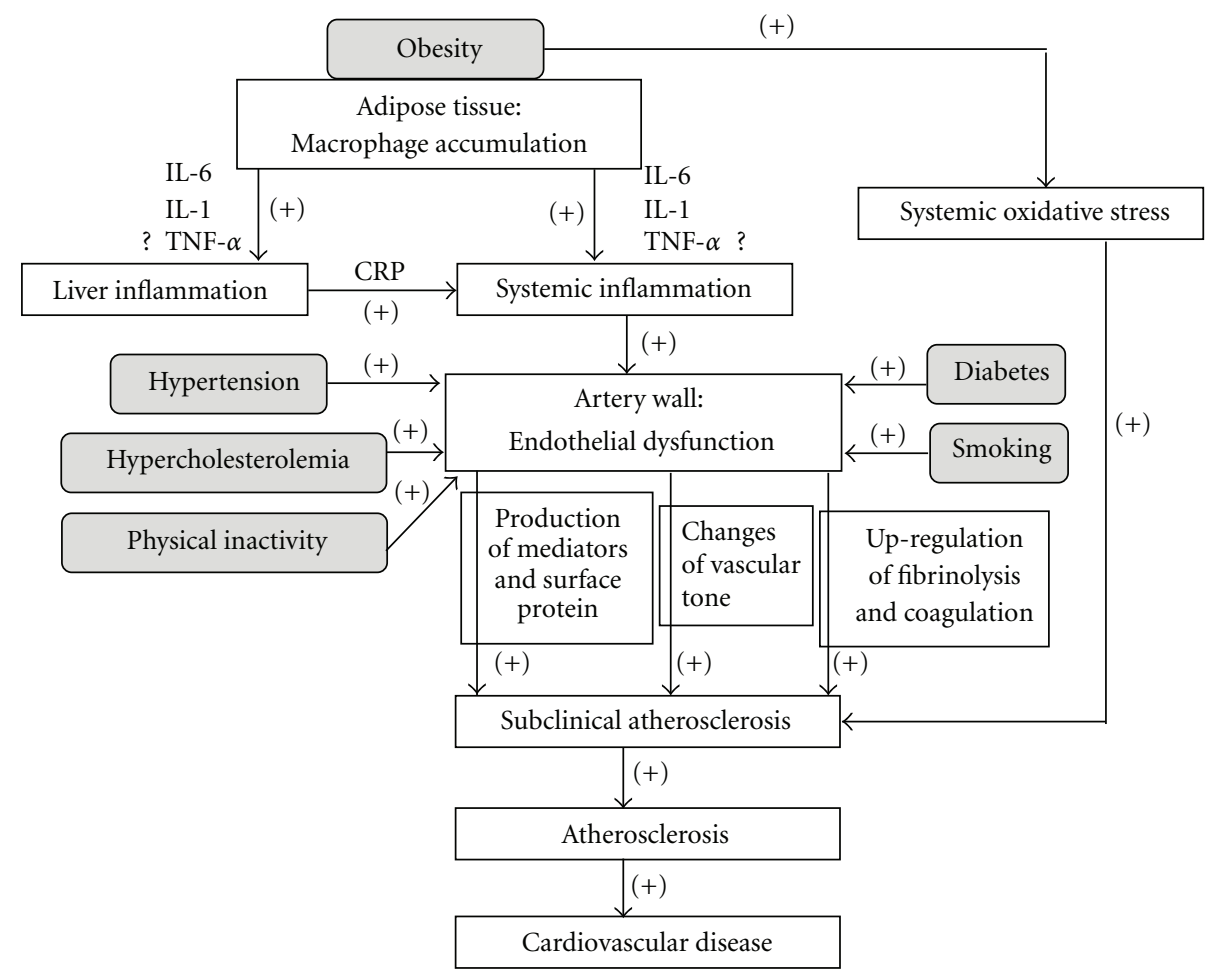

FIGURE 2: Mechanism of the relationship between inflammation induced by obesity and cardiovascular disease. Gray box shows the traditional cardiovascular disease (CVD) risk factors. The arrow and plus symbols indicate the enhanced courses. Smoking, obesity, hypertension, diabetes, physical inactivity and hypercholesterolemia are established risk factors of CVD. In obese individuals, macrophages first accumulate within the adipose tissue, leading to local inflammation. As the obesity increases, several proinflammatory factors, including IL-1, IL-6 and TNF- $\alpha$, are produced in the adipose tissue. Macrophage accumulation and the subsequent local inflammation are believed to result in numerous metabolic dysfunctions that typically accompany obesity, including systemic inflammation. Endothelial dysfunction occurs during the early stages of atherosclerosis and is responsible for the pathophysiological changes in subclinical atherosclerosis, which include changes in a variety of mediators, surface proteins, and in autacoids that are involved in vasomotion, coagulation and inflammation. Obesity also can increase systemic oxidative stress independently of blood glucose and diabetes. One of the major events of atherosclerosis is CVD.

problems associated with obesity are generally related more to the central (abdominal, visceral) distribution of fat rather than to the amount of fat, and the distribution of fat differs between males and females $[17,18]$. Men exhibit a more central accumulation of fat, whereas women exhibit a more gluteal/femoral accumulation. The original definition of obesity for males (android type) and females (gynoid type) dates to the first clinical observations made by Vague in 1947. The greatest health risk is associated with fat distribution in the central or upper body (android) parts. Recent research $[19,20]$ has shown that sex hormones play an important role in obesity and that there are differences in the occurrence of insulin resistance and heart diseases that are dependent upon gender. Findings have indicated that both the total amount of fat that an individual carries and the distribution of that fat are important. At present, it is difficult to accurately measure fat in the body, and there is currently no simple method available for routine clinical use.

Epidemiological and clinical evidence strongly suggests a major role for sex steroid hormones in the regulation of adipose tissue distribution. Sex steroid hormones, such as estrogen, progesterone, and androgen, are involved in the metabolism, accumulation, and distribution of adipose tissues. Normal distribution of body fat occurs when sex steroid hormones are present. If a decrease in sex steroid hormones occurs, such as that seen during aging or gonadectomy, there is a greater tendency for obesity states, in addition to increases in major risk factors for CVD.

\section{Mechanisms of the Relationship among Obesity, Inflammation, and CVD}

4.1. Systemic Inflammation. As individuals become obese and their adipocytes enlarge, the adipose tissue undergoes molecular and cellular alterations that subsequently affect systemic metabolism (Figure 2). First, macrophages accumulate within adipose tissue, leading to local inflammation. Several proinflammatory factors are produced in adipose tissue as obesity increases. When compared to lean individuals, adipose tissue in obese individuals shows higher expression of proinflammatory proteins, including TNF- $\alpha$ and IL$6[21,22]$. Macrophage numbers in adipose tissue also increase with obesity [23], apparently acting as scavengers 


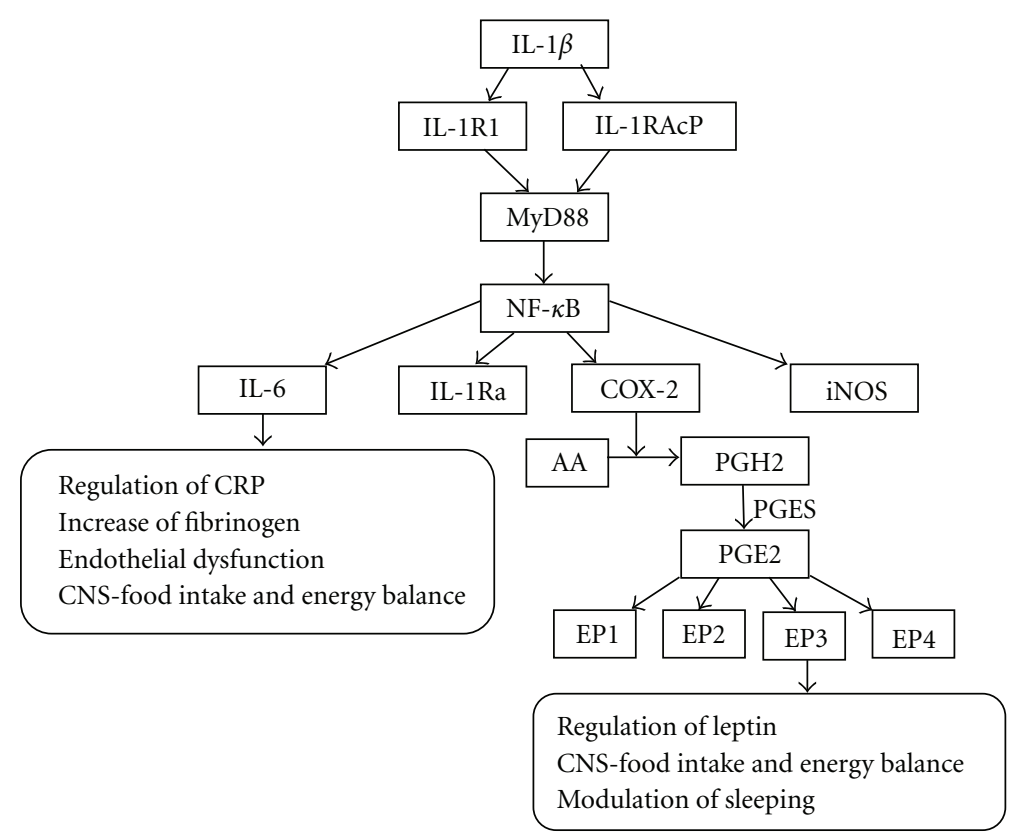

FIGURE 3: Interleukin-1 $\beta$ (IL-1 $\beta$ ) induction of interleukin-6 (IL-6) and prostaglandin E2 (PGE2) signaling. IL-1 $\beta$ binds to the IL-1R1/IL$1 \mathrm{R} 1 \mathrm{AcP}$ heterodimer, which then initiates the signaling cascade that causes the translocation of the transcription factor nuclear factor- $\kappa \mathrm{B}$ $(\mathrm{NF}-\kappa \mathrm{B})$ into the nucleus, where it induces the transcription of pro- and anti-inflammatory genes including inducible nitric oxide synthetase (iNOS), IL-6, IL-1Ra and cyclooxygenase-2 (COX-2). COX-2 catalyses the conversion of arachidonic acid (AA) to prostaglandin H2 (PGH2). PGH2 is converted into PGE2 by terminal PGE synthase (PGES). PGE2 signals occur via four different G-protein coupled receptors, EP1REP4R, each of which has multiple splice variants with different signaling properties.

of apoptotic adipocytes. It also has been reported that there is a marked increase in these scavengers in obese subjects [24]. Macrophage accumulation and the subsequent local inflammation are believed to result in numerous metabolic dysfunctions that accompany obesity, including systemic inflammation and atherosclerosis.

Visceral fat secretes more cytokines than subcutaneous adipose tissue [16]. A recent study elegantly demonstrated that transplantation of visceral adipose tissue from genetically obese mice into Apoe-deficient mice increased atherosclerosis in the recipient animals, suggesting that inflamed adipose tissue exerts distinct vascular effects, presumably through inflammatory cells such as macrophages within the visceral adipose tissue [25]. Macrophages within visceral adipose tissue are known to express and release cytokines. These cytokines reach the liver though the portal circulation, where they can stimulate hepatic inflammation [26], thereby inducing a chronic systemic inflammatory response.

4.2. Endothelial Dysfunction. Clinical and experimental data support a link between systemic inflammation and endothelial dysfunction. Mounting evidence shows that disturbed endothelial function may be an early marker of an ongoing atherosclerotic process. Thus, endothelial dysfunction has increasingly been recognized to play an important role in a number of conditions associated with a high prevalence of atherosclerotic CVD. Inflammatory cytokines are important protagonists in the formation of atherosclerotic plaques, eliciting effects throughout the atherosclerotic vessel. Importantly, the development of atherosclerotic lesions, regardless of risk factors (e.g., diabetes, hypertension, obesity), is characterized by the disruption of the normal function of endothelial cells.

The reasons for coronary endothelial dysfunction are complex and may involve ischemia/reperfusion injury. Smoking, obesity, hypertension, diabetes, physical inactivity, and hypercholesterolemia are established atherogenic risk factors. Endothelial dysfunction is regarded as an early stage of atherosclerosis, which is a chronic inflammatory disease [27]. Chronic inflammation is a major contributing factor to atherosclerosis and various markers of inflammation, fibrinolysis, and coagulation are upregulated in patients with established atherosclerotic disease. For vascular homeostasis, endothelial cells are of the utmost importance and they produce a variety of mediators, surface proteins, and autacoids involved in vasomotion, coagulation, and inflammation. Adipose tissue expresses enzymes involved in the angiotensin system (RAS) (renin, angiotensin-converting enzyme (ACE)), as well as the nonrenin-angiotensin system (NRAS) (cathepsin D, cathepsin G, tonin, chymase) [28]. The identification of elevated CRP as a transient independent risk factor for endothelial dysfunction might provide an important clue for linking a systemic marker of inflammation to the progression of atherosclerotic disease. Thus, CRP has been proposed for risk assessment of CVD in the at-risk general population. Available evidence suggests that low-grade inflammation is accompanied by decreased 
bioavailability of endogenous NO and that TNF- $\alpha$ may play a key role in these events. The adipose tissue constitutes a source of other vasoactive factors, such as leptin, serum amyloid A (SAA), or apelin, among others [29]. Since blood vessels express receptors for most of the adipocytederived factors, adipose tissue seems to play a key role in cardiovascular physiology via the existence of a network of local and systemic signals. Therefore, these data demonstrate that markers of inflammation have independent predictive value for clinical and subclinical CVD beyond that of the traditional risk factors.

4.3. Subclinical Atherosclerosis and CVD. The development of atherosclerosis in obesity stems from a constellation of interrelated proatherogenic mechanisms. It is well established that a higher BMI is associated with subclinical inflammation, as reflected by increased CRP levels [30], and increased systemic oxidative stress that is independent of blood glucose and diabetes [31]. Recent evidence has suggested that leptin stimulates cholesterol uptake by macrophages, particularly in the presence of high glucose. This then triggers the formation of foam cells and the development of atheromatic lesions. Obesity-related hypoadiponectinemia might also contribute to impaired endothelial function, increased vascular ROS production and overall proatherogenic effects [32]. Finally, increased release of proinflammatory cytokines by adipose tissues, including IL-6, IL- 1 , and TNF- $\alpha$, sustains vascular wall inflammation and promotes pro-atherogenic gene expression [33].

There is interest in identifying markers of subclinical atherosclerosis, such as coronary artery calcium (CAC) and carotid intimal medial thickness (CIMT), in order to facilitate an earlier diagnosis and possible prevention of CVD. CRP levels were found to be correlated with CIMT in a group of young subjects [34], but not in older individuals [35]. In other studies, levels of IL- 6 have been shown to be associated with the amount of CAC [36], and the CD40 ligand, which is a marker of enhanced innate immunity, has been found to be correlated with CIMT in human subjects [37]. Since leptin levels have been shown to be associated with CAC independently of body weight measures or other risk factors, this points to a possible proatherogenic role for leptin [38].

\section{Adipose Tissue-Derived Cytokines Known to Affect Inflammation}

5.1. CRP. Of the many positive and negative acute-phase reactants, perhaps the most recognized is CRP, which is a member of the pentraxin family that attaches to the plasma membrane of damaged cells causing cell death through activation of the complement cascade [39]. More than 20 prospective epidemiologic studies have demonstrated that high-sensitivity CRP is an independent predictor of myocardial infarction, stroke, peripheral arterial disease, and sudden cardiac death, even in apparently healthy individuals [40, 41]. Clearly, CRP is one of the strongest markers of chronic inflammation, and it has been reported that it also directly participates in the coronary and aortic atherosclerosis that leads to cardiac events [42].

Ouchi et al. [43] confirmed CRP mRNA expression in human adipose tissue using quantitative real-time polymerase chain reaction. In the same article, the authors proposed that adipose tissue is an important source of circulating CRP. However, they made no attempt to investigate the stimuli able to induce CRP. Esposito et al. [44] investigated the effects of weight loss and lifestyle changes on vascular inflammatory markers in obese women. After 2 years, they found that BMI, as well as the serum concentrations of IL-6, IL-18, and CRP, decreased more in the intervention group than in the control subjects, whereas the adiponectin levels significantly increased. The beneficial effects of a Mediterranean-style diet on endothelial function and vascular inflammatory markers have been documented in patients with metabolic syndrome. When compared to patients consuming a control diet, patients consuming a Mediterranean-style diet have significantly lower serum concentrations of high-sensitivity CRP, IL-6, IL-7, and IL-18 as well as a decreased insulin resistance [45]. In a quartile analysis of the percent weight reduction, the largest weight reduction quartile did not show significant decreases in the CRP levels, whereas the middle quartiles showed remarkable CRP decreases. Based on inflammatory status, there may be an optimal pace of exercise combined with weight loss [46]. Two recent studies have demonstrated that exercise training in conjunction with weight reduction significantly affected the CRP levels, body composition, and human left ventricular growth $[47,48]$.

5.2. Serum Amyloid A (SAA). Serum amyloid A (SAA), an important marker of inflammation, is an apolipoprotein that is mainly synthesized in mammalian liver [49]. Human SAA is a $12.5-\mathrm{kDa}$ protein whose levels can increase up to 1,000 - fold in the serum $24-36 \mathrm{~h}$ after infection or injury, decline after 4-5 days, and then return to baseline after 10-14 days [50]. The human genome encompasses four SAA genes, of which three encode functional proteins. SAA1 and SAA2 are highly homologous reactants whose concentration can increase upon infection, trauma, and obesity [51, 52], whereas SAA3 is a pseudogene and SAA4 is a constitutively expressed minor constituent of the nonacute-phase HDL [53].

SAA has proven to be a suitable and sensitive indicator of the various stages of inflammation involved in inflammatory disorders. SAA is comparable to CRP, as both are major acute phase proteins that can increase up to 1,000-fold and reach $1 \mathrm{mg} / \mathrm{mL}$ in the serum under stimulation [50]. They can be produced by the liver under inflammatory stimuli, and their effects are mediated through pro-inflammatory cytokines (IL-1 and TNF- $\alpha$ ) and "messenger" cytokines (IL6) [54]. However, in contrast to CRP, which is mainly expressed in the human liver, SAA is expressed in both the liver and adipose tissue. SAA is now accepted as an adipokine that is produced by adipocytes and which directly mediates obesity-associated inflammation. Hence, SAA might serve as a better indicator of obesity and obesity-associated diseases, 
especially when vascular diseases and metabolic disorders are present.

SAA is known to be a marker for obesity, as its expression is well correlated with obesity [55]. Some studies have shown that SAA levels are positively associated with BMI levels and that weight loss led to decreased SAA levels. In 1999, Danesh et al. [56] first reported that concentrations of SAA protein were strongly correlated with obesity. Since then, more than ten studies have shown that SAA is strongly associated with obesity [57-59]. In addition, it has been shown that SAA gene expression is increased in the adipose tissue of obese subjects and is significantly correlated with adipocyte size and inflammatory biomarkers [52].

Recent studies have shown that SAA elevation can predict cardiovascular events analogously with or even better than CRP by itself [60-62] and in this sense, it has been speculated that SAA might be one of the links or even a proatherogenic risk factor between inflammation and CVD $[63,64]$. SAA is able to both alter vascular proteoglycans in a proatherogenic manner [65] and stimulate the production of various inflammatory mediators in cultured vascular endothelial cells, neutrophils, and monocytes [66]. Endothelial cells, smooth muscle cells, monocytes, and macrophages in atherosclerotic lesions have been reported to account for the extrahepatic production of SAA, as the presence of both SAA mRNA and protein products have been detected in these cell types [67]. SAA has also been accepted as being a biomarker of cerebrovascular disease and carotid artery intima-media thickness, which is an early index of atherosclerosis [68-71]. However, a very recent study indicated that SAA does not mediate early atherosclerosis [57].

SAA has also been found to be associated with metabolic disorders, such as diabetes, insulin resistance, and metabolic syndrome $[72,73]$. Additionally, genes critical for insulin sensitivity were also found to be downregulated in adipocytes treated with recombinant SAA [74].

5.3. Leptin. Leptin, which was the first adipocyte hormone identified, influences food intake through direct effects on the hypothalamus [75]. The adipocyte-derived hormone leptin has actions in the brain (e.g., hypothalamus, cortex and limbic areas) and in a number of peripheral tissues as well (e.g., cells of the pancreas, liver and immune system). However, the central action of leptin in the brain, and in particular the hypothalamus, has been best characterized with regards to energy homeostasis and its importance for reproductive functions [76]. Moreover, disruption of peripheral leptin signaling in mice has been shown to cause no significant changes in either the energy balance or glucose homeostasis [77].

Mice lacking the gene coding for leptin (named $o b / o b$ mice) are obese and diabetic. When $o b / o b$ mice are treated with regular injections of leptin, they show reduced food intake, increased metabolic rate, and weight loss [78]. These effects appear to be mediated mainly by the central nervous system, as intracerebroventricular injection of leptin produces significant effects at much lower doses than those required by systemic injection. Systemic injections of leptin have a beneficial effect in children with congenital leptin deficiencies [79]. In a pioneering study, administration of exogenous leptin to individuals with lipoatrophic diabetes resulted in marked reductions in triacylglycerol concentrations, liver volume, and glycated hemoglobin. Ultimately, this treatment resulted in the discontinuation of or large reductions in the patient's antidiabetic therapy [80]. Unfortunately, leptin concentrations are already high in most obese individuals because of the increased amount of leptinsecreting adipose tissue [81]. In these individuals, increasing the leptin concentrations only induces the target cells to become resistant to actions of the hormone. Therefore, further studies need to be undertaken to clarify potential therapeutic strategies using leptin in these types of patients.

Leptin is involved in the control of not only energy homeostasis but also immunity. During fasting/starvation, when plasma leptin levels decline, neural pathways in the hypothalamus cause the appetite to increase and energy expenditure to decrease as the body attempts to restore its fat stores [82]. In addition, the fall in plasma leptin diminishes thyroid hormone production and inhibits the reproductive axis, both of which help to save energy during nutritionally lean times [83]. These metabolic effects of leptin are in part centrally mediated by activation of the hypothalamic-sympathetic nervous system axis [84]. In addition to the complete leptin deficiency disorder, relative leptin deficiency is an emerging clinical syndrome that is now being seen more often in several clinical conditions, including congential or acquired lipodystrophy as well as exercise-induced energy deficiency and hypothalamic amenorrhea or anorexia nervosa. Leptin replacement therapy might prove to be a therapeutic option for patients with these disorders [85]. Very recently, administration of chemical chaperones that decrease ER stress also restored leptin sensitivity in diet-induced obese mice [86]. In obese subjects who have lost weight, modifications that lead to decreased energy expenditure may predispose the individual to regain the weight. However, when subjects are administered "replacement" doses of leptin that restore their circulating leptin concentrations to preweight-loss levels, the weight gain can be prevented [87]. This suggests that the weight-reduced state is a condition of relative leptin deficiency. Recent reports have shown that in addition to its action on the hypothalamus, leptin may also act on the cortex and limbic areas, which are involved in cognitive and emotional regulation of feeding behavior [88]. Teleologically, the adaptations mediated by reduced leptin may have evolved as a protection against the threat of starvation by limiting energy use and enhancing energy storage [89].

The potential effects of leptin in the pathophysiology of cardiovascular complications of obesity remain diverse [90]. While some studies $[91,92]$ have indicated that circulating leptin levels are not significantly related to the risk of CVD or mortality in a diabetic population, these studies did find that leptin was associated with obesity and inflammatory markers. Even so, other reports have suggested that leptin does contribute to atherosclerosis and CVD in obese subjects 
[93]. Therefore, this protein may elevate the blood pressure by stimulating the autonomic nervous system. Leptin has been found to have multiple effects on the cells of the artery wall. In human vascular endothelial cells, leptin upregulates the expression of the plasminogen activator inhibitor-1 [94], and leptin also helps modulate ACAT1 expression and cholesterol efflux from human macrophages [95]. In addition, leptin has been reported to increase nitric oxide (NO) bioavailability in blood vessels via the activation of endothelial NO synthase (eNOS) [96] and inducible NO synthase (iNOS) [97] in the endothelial and smooth muscle cells, respectively. Recent studies that measured coronary artery disease have demonstrated that hyperleptinemia was associated with coronary atherosclerosis $[98,99]$, with the association determined to be independent of insulin resistance. Other studies have shown that leptin may have a role in neointimal formation in response to arterial injury $[100,101]$. In fact, very obese, leptin-deficient mice have been found to be protected from atherosclerosis despite all of the metabolic risk factors, suggesting that this hormone may directly contribute to the risk of vascular disease [102]. Moreover, in a prospective study in humans in which anthropometric and metabolic risk factors were controlled, the circulating leptin concentrations were shown to be an independent risk factor for predicting cardiovascular events [103]. Therefore, when chronically elevated concentrations of leptin are seen in obese individuals, this may indicate a predisposition to progression of atherosclerosis in these individuals.

5.4. Adiponectin. Adiponectin is a product of adipocytes, and its levels in humans decrease in obese subjects [104]. As one of the most extensively studied adipokines, adiponectin has 3 different oligomers, each of which may have a different biological function [105]. The major receptors for adiponectin are AdipoR1 and AdipoR2. These belong to a new family of receptors that are predicted to contain seven transmembrane domains but which will be structurally and functionally distinct from the G-protein coupled receptors. A recent study has shown that AdipoR2 stimulates energy dissipation by increasing fatty acid oxidation while inhibiting oxidative stress and inflammation [106, 107]. Adipocytes secrete high levels of adiponectin that then exert anti-inflammatory effects, most notably in atherosclerotic plaques [108]. These effects occur due to the suppression of TNF- $\alpha$ and proinflammatory cytokines such as IL-6 and interferon-c, along with the induction of other anti-inflammatory factors such as the IL-1 receptor antagonist [109]. In contrast, adiponectin levels have been shown to be low in several different forms of insulin resistance. In vivo, adiponectin enhances energy consumption and fatty acid oxidation in the liver and muscle, which reduces the tissue triglyceride content, thereby further enhancing the insulin sensitivity [110]. In adiponectin transgenic mice, there is improvement of the lipid profile [111, $112]$, and when plasma triglycerides are reduced, this leads to an increased VLDL catabolism in the skeletal muscle [113]. Taken together with its metabolic and anti-inflammatory effects, it has been proposed that adiponectin not only contributes to the beneficial effects of body weight loss but also has a role in modulating the cardiovascular system.

As might be expected based on the above observations, adiponectin promotes an antiatherogenic and antiinflammatory program of gene expression and function in the vessel wall. Adiponectin downregulates the expression of adhesion molecules on the endothelial cells and directly improves endothelial dysfunction $[114,115]$. Adiponectin also reduces proliferation in a receptor-independent fashion in the vascular smooth muscle cells [116]. In a very recent study, it has been shown that adiponectin reduces lipid accumulation, down-regulates the expression of scavenger receptors in macrophages, and promotes macrophage polarization, all of which play a role in anti-inflammatory activities [117]. Other studies have also indicated that adiponectin has an important role in cardiovascular protection. Hypoadiponectinemia is found in patients with angiographically demonstrated coronary artery disease [118]. In obese children, it has been reported that reduced adiponectin concentrations are of more importance than conventional cardiovascular risk factors, and that this inflammation status is related to early atherosclerosis [119]. However, in a large prospective study that was combined with a meta-analysis of previously published prospective studies, the adiponectin levels at baseline were found to be rather weak predictors of CVD risk [120]. However, other studies have shown that adiponectin exerts beneficial effects at nearly all stages of the atherogenesis process [121], and that the adiponectin levels are inversely correlated to the progression of the coronary artery calcium in both diabetic and nondiabetic subjects [122]. Serum total and high-molecular weight adiponectin are also associated with biomarkers of inflammation, insulin resistance, and endothelial function, all of which are independent risk factors of CVD [123].

5.5. Resistin. Resistin, which is one of the most recently identified adipokines, has been proposed to be an inflammatory marker for atherosclerosis. While it has been shown to induce increases in CRP production by the macrophages [124], resistin is an example of the new adipokines that appear to have contrasting roles when examined in mice versus humans. For example, confirmation of the results found in mice has proven to be difficult in human populations. This may be due to the fact that resistin appears to be derived from different sources in humans as compared to rodents. This protein was initially shown to be released in large amounts from mouse adipocytes, with obese mice having elevated levels that were accompanied by insulin resistance [125]. However, investigations in humans suggest that resistin is expressed in adipocytes with monocytes and macrophages [126, 127]. This lack of homology between the human and mouse resistin genes suggests a potential divergence in function [128]. Since macrophages are known inflammatory modulators, resistin may be an inflammatory marker in humans. Supporting this possible inflammatory role in humans are results that show recombinant resistin activates human endothelial cells, as measured by an increased expression of endothelin-1 and various adhesion 
molecules and chemokines, while simultaneously increasing the CD40-ligand signaling by down-regulating the tumor necrosis factor receptor-associated factor-3 [129]. Moreover, Calabro et al. [130] has shown that resistin can promote human coronary artery smooth muscle cell proliferation by activation of the extracellular signal-regulated kinase $1 / 2$ (ERK) and phosphatidylinositol 3-kinase (PI3 K) pathways. Taken together, these findings suggest a possible mechanistic link between resistin and cardiovascular disease via proinflammatory pathways.

In addition, there have been many recent reports that support a role for resistin in obese rodent models. Resistin has been found to modulate nutritional regulation and may possibly play a role in maintaining fasting blood glucose levels [131]. Further rodent studies have also suggested that resistin mRNA levels are higher in abdominal fat depots, as compared to deposits in the thigh [132], and that these serum resistin levels are positively correlated with BMI [133]. Recent investigations in humans have shown there are higher serum resistin levels in obese subjects as compared to lean subjects. These higher levels were also positively correlated with changes in the BMI and the visceral fat area [134, 135]. Lee et al. [136] found higher circulating resistin levels in obese mice when compared to their lean counterparts. Additional studies have reported significant reductions in circulating resistin levels following moderate weight loss [137] and postgastric bypass [138]. Collectively, these observations suggest that resistin may indirectly be involved in the nutritional regulation in humans.

5.6. Visfatin. Visfatin, also known as nicotinamide phosphoribosyltransferase (NAMPT), which was previously known as a pre-B cell colony-enhancing factor (PBEF), functions as a growth factor for early B cells within the immune system [139]. Fukuhara et al. [140] demonstrated that visfatin is a secreted protein that is expressed and regulated by the adipose tissue. As compared to subcutaneous adipose tissue, there are greater amounts of visfatin within visceral fat depots. Furthermore, this study indicated that visfatin could bind to and activate insulin receptors, similar to that seen for insulin both in vivo and in vitro. However, this effect of visfatin is controversial. For example, Revollo et al. were unable to reproduce the insulin-mimetic activity of this protein, even though a significant physiological role in the regulation of beta-cell function through the NAD biosynthetic activity was detected. Thus, the authors suggested that NAMPT could play an important role in the control of glucose metabolism [141]. After these novel findings, Fukuhara et al. decided to retract their previously published paper [142].

The visfatin peptide was originally discovered in the liver, skeletal muscle, and bone marrow and found to act as a growth factor for B-lymphocyte precursors. This peptide is not only produced by white adipose tissue (WAT), but also by endotoxin-challenged neutrophils, and is able to prevent apoptosis via a mechanism mediated by caspases 3 and 8 [143]. Circulating visfatin levels are closely correlated with WAT accumulation and visfatin mRNA levels increase in the course of adipocyte differentiation. Visfatin expression is upregulated by IL- 6 and TNF- $\alpha$, and is down-regulated by GH [144]. Insulin has no effect on visfatin mRNA [145]. Moreover, visfatin is up-regulated by the peroxisomal proliferatoractivated receptor (PPAR)-alpha and PPAR-gamma agonists in obese rats. Since it has been shown to be associated with improved glycemic control and lipid profiles, this suggests that PPAR-alpha and PPAR-gamma agonists may act, at least in part, via the up-regulation of visfatin expression [146]. In addition to inducing chemotaxis and the production of IL-1, TNF- $\alpha$, IL- 6 , and costimulatory molecules by CD14C monocytes, visfatin also increases their ability to induce alloproliferative responses in lymphocytes, effects which are mediated intracellularly by p38 and MEK1 [144].

Possible associations between circulating visfatin and anthropometric or metabolic parameters in obesity and type 2 diabetes have been found in some but not all reported studies [147-149]. These contradictory findings may be due in part to the considerable differences found in the visfatin immunoassays [150]. In human studies, it has been shown there is a positive correlation between the visceral adipose tissue visfatin gene expression and BMI, along with a negative correlation between BMI and subcutaneous fat visfatin [151]. This suggests that visfatin regulation varies within different depots and that the adipose depot ratios are highly dependent upon the obesity of the subjects. A wide population study in humans has recently discovered a direct correlation between plasma visfatin and the BMI and body fat content in males only. This study failed to find any differences in the expression between the visceral and subcutaneous fat depots [152].

Several studies have shown that there are different disorders that exhibit altered plasma levels of this protein [153156]. Thus, visfatin plasma concentrations may potentially be related to lipid metabolism [157] and the inflammatory response [158]. Since an increased expression of this protein has been observed in the macrophages of unstable carotid and coronary atherosclerosis in humans [159], and there is a negative association between the visfatin plasma levels of visfatin and vascular endothelial function [160], it has been proposed that visfatin plays a role in plaque destabilization. NAMPT, which was originally identified as PBEF, has been shown to act as a cytokine independent of its enzymatic activity, and thus plays a major part in regulating immune responses [161]. Since NAMPT has been implicated in the pathogenesis of several acute or chronic inflammatory conditions, such as atherosclerosis and CVD [161], it may act as a pro-inflammatory cytokine and potentially have a beneficial effect on insulin secretion.

At the present time, the role of visfatin in the modulation of glucose metabolism, as well as its ability to bind to the insulin receptor is still under debate [162-164]. As a number of inconsistencies among the different visfatin studies exist, the role of this adipokine in obesity and insulin resistance has yet to be clearly defined.

5.7. Chemerin. Recently, chemerin (retinoic acid receptor responder 2, tazarotene-induced gene 2) was found to be 
highly expressed in adipose tissue and liver [165]. Chemerin is an agonist of the orphan G-protein coupled receptor chemokine-like receptor 1 (CMKLR1, ChemR23) [166] that is expressed by cells of the innate immune system [167]. Therefore, chemerin might be further evidence of a link between obesity and inflammation. Chemerin is secreted as an inactive precursor, and then activated through proteolytic cleavage by serine proteases of the coagulation, fibrinolytic and inflammatory cascades. Chemerin appears to be a novel and promising adipokine, and in several recent studies, human chemerin plasma levels have been shown to have a significant association with the BMI, inflammation, and metabolic syndrome [168-170].

Platelets have been found to be a rich cellular source of chemerin. In some pathological conditions, chemerin is activated and then released, which leads to the elevation of blood chemerin levels [171]. Recent studies have shown that both adipocytes [172] and fibroblast cells [173] can produce chemerin. Chemerin has also been measured in a number of human inflammatory exudates, including ascitic fluids from human ovary cancer and liver cancer, as well as synovial fluids from arthritic patients [174]. Angiotensin-converting enzyme (ACE) may be responsible for the activation of prochemerin. If so, as has been shown in vitro, this effect should be able to be blocked by an ACE inhibitor such as captopril [175]. However, further studies will be necessary to clarify this potential mechanism in vivo. There is also growing evidence that the bioactivity of chemerin is closely regulated by proteolytic cleavage in the $\mathrm{C}$ terminal region, which may control its maximal chemotactic or anti-inflammatory effects [176]. While the primary amino acid sequences indicate that chemerin is structurally distinct from the CXC and CC chemokines, it functions exactly like a chemokine and can induce leukocyte migration and intracellular calcium mobilization. Chemerin also exerts potent anti-inflammatory effects on activated macrophages, which express the chemerin receptor CMKLR1 (chemokinelike receptor-1) in a cysteine protease-dependent manner [177].

Chemerin is a newly described adipokine with effects on adipocyte differentiation and metabolism in vitro [165]. In rodents, there is conflicting data with regard to the association of chemerin with obesity and diabetes. While there is a decreased chemerin expression in the adipose tissue of $\mathrm{db} / \mathrm{db}$ mice as compared with controls [178], chemerin expression is significantly higher in the adipose tissue of impaired glucose tolerant and diabetic Psammomys obesus as compared with normal glucose-tolerant sand rats [179]. It has also been demonstrated that chemerin or chemerin receptor knockdown impairs the differentiation of 3T3-L1 cells into adipocytes, reduces the expression of adipocyte genes involved in glucose and lipid homeostasis, including adiponectin and leptin, and alters the metabolic functions in mature adipocytes [170]. In humans, no significant differences were noted for the chemerin levels between subjects with type 2 diabetes and normal controls. However, in normal glucose-tolerant subjects, chemerin levels were significantly associated with BMI, triglycerides, and blood pressure [179]. Plasma chemerin levels in normal subjects are also significantly associated with BMI, circulating triglycerides, and blood pressure, suggesting a strong relationship of this protein with obesity-associated complications [179].

It is possible that visceral fat may potentially contribute to the chronic inflammation that is observed in obese individuals. However, only a few studies have investigated the adipokine concentrations in the portal circulation [180]. In order to be able to determine the physiological role of chemerin in the glucose metabolism, and to identify chemerin's target tissues as well as relevant signal transduction pathways, further studies will need to be undertaken.

5.8. Omentin, Apelin, Vaspin, and Retinol-Binding Protein 4 (RBP4). Omentin, which was originally referred to as intelectin and first found in the intestinal Paneth cells, has a predicted molecular weight of $33 \mathrm{kDa}$ [181]. Omentin is a fat depot-specific secretory protein synthesized by the visceral stromal vascular cells, but not the adipocytes. It has also been found in the human lung, intestine, and heart [182] and is strongly expressed in the human ovaries and placenta [183]. This new adipokine is codified by two genes ( 1 and 2) and is highly and selectively expressed in the visceral adipose tissue. In obesity, omentin 1 plasma levels and the adipose tissue gene expression are decreased, and there is a positive correlation with the plasma adiponectin and high-density lipoprotein. These levels were negatively correlated with waist circumference, BMI, and insulin resistance [184, 185]. Administration of glucose and insulin to human omental adipose tissue explants resulted in a dose-dependent reduction of the omentin-1 expression. Furthermore, prolonged insulin-glucose infusion in healthy individuals resulted in significantly decreased plasma omentin-1 levels [186]. Recombinant omentin enhances the uptake of glucose in isolated adipocytes and dramatically increases the insulin induction of Akt/PKB phosphorylation [182]. However, further studies need to be undertaken, as the physiological role of omentin in glucose metabolism along with omentin's target tissues, receptor, and the relevant signal transduction pathways have yet to be determined.

Apelin is a bioactive peptide that is produced by adipocytes, vascular stromal cells, the heart, and the cardiovascular system [187]. In humans, both obesity and insulin significantly elevate the plasma levels of apelin and this peptide appears to act as a circulating and paracrine hormone [187]. The gene that encodes the apelin, receptor shares the greatest sequence identity with the angiotensin AT1 receptor [187]. In experimental animal models of heart failure, the cardiac apelin system is down-regulated by angiotensin II, while restoration is achieved after treatment with an angiotensin type 1 receptor blocker [188]. In the cardiovascular tissues of rats, apelin production is upregulated by hypoxia [189] and ischemic cardiomyopathy [190], which perhaps may be a compensatory mechanism. In spontaneously hypertensive rats, exercise training has also been shown to up-regulate the apelin production [191]. Apelin has a positive hemodynamic effect, as it acts an inotrope in both normal and failing rat hearts and in isolated cardiomyocytes $[192,193]$. Apelin may be able to 
regulate insulin resistance by facilitating the expression of brown adipose tissue uncoupling proteins and by altering adiponectin levels [194]. Decreased plasma apelin levels have been observed in patients with lone atrial fibrillation [195] and chronic heart failure [196]. Cardiac resynchronization therapy has been used to treat these patients successfully, with increases in the apelin levels observed after initiation of the therapy [197].

Vaspin is a member of the serine protease inhibitor family. This adipocytokine has been isolated from the visceral adipose tissue of Otsuka Long-Evans Tokushima Fatty (OLETF) rats that are at an age when the body weight and hyperinsulinemia has peaked [198]. OLETF rats are commonly used as a model of human type 2 diabetes. This model also shares common components of the human metabolic syndrome, including abdominal obesity, insulin resistance, hypertension, and dyslipidemia [199]. Vaspin production decreased at the same time the diabetes worsened and body weight fell in the untreated OLETF rats. However, when the animals were treated with insulin or pioglitazone, serum vaspin levels were maintained [198]. This suggests that the up-regulation of vaspin may have a defensive action against insulin resistance. Human vaspin mRNA has been reported to be expressed in the visceral and subcutaneous adipose tissue. In addition, it has been shown to be regulated in a fat-depot specific manner, and to be associated with obesity and parameters of insulin resistance [200, 201]. It has also been reported that elevated vaspin serum concentrations are correlated with obesity and impaired insulin sensitivity, whereas type 2 diabetes appears to abrogate this correlation $[202,203]$. Vaspin expression decreases in conjunction with a worsening of the diabetes and a body weight loss. These studies indicated that vaspin might play a causative role in the development of obesity and metabolic disorders or, at least, be a biomarker for these diseases. In order to clarify these potential mechanisms, further investigation using more sophisticated methods will need to be undertaken.

Using the adipose-specific Glut4 knockout (adiposeGlut4(-/-)) mice model, retinol-binding protein 4 (RBP4) has been identified as a highly expressed circulating adipokine that causes insulin resistance when it is overexpressed or injected into mice [204]. In the circulation, RBP4 is bound to transthyretin, which causes decreases in the RBP4 renal clearance. In ob/ob mice, there was a 4 -fold increase in transthyretin plasma levels as compared to lean mice or dietinduced obese mice [205]. A large number of subsequent studies confirmed there was an association between increases in the circulating RBP4 levels and various aspects of adiposity [206], insulin resistance [207, 208], diabetes mellitus [209], and metabolic syndrome $[210,211]$. However, there are also other studies that have been unable to establish these associations $[212,213]$. The reason for this discrepancy may be explained in part by the different methods that were used to measure the RBP4 and the different populations employed in these various studies. In some very recent studies, it has been reported that increased plasma RBP4 levels are associated with inflammatory cardiomyopathy [214] and cerebral infarction [215]. Therefore, at the current time, whether RBP4 functions as an adipokine in humans and exerts metabolic effects on glucose metabolism remains uncertain. Further studies will need to be performed in order to clarify RBP4's exact role in humans.

\section{Conclusions}

The worldwide incidence of obesity has markedly increased during recent decades. Obesity and associated disorders now constitute a serious threat to the current and future health of all populations on earth. Obesity represents a major risk factor for diseases including CVD, atherosclerosis and diabetes, in which inflammation acts as a major driver in the pathogenesis. Both adipocytes and macrophages within fat tissue secrete numerous cytokines that may contribute to the characteristic pathophysiological changes. By expanding our knowledge on inflammation and the link between obesity and CVD, this should make it possible to improve our understanding of the pathophysiology of obesity.

\section{References}

[1] J. R. Sowers, "Obesity as a cardiovascular risk factor," The American Journal of Medicine, vol. 115, no. 8, pp. 37-41, 2003.

[2] The World Health Report 2002, Reducing Risks, Promoting Healthy Life, World Health Organization, Geneva, Switzerland, 2002.

[3] N. Aoi, M. Soma, T. Nakayama et al., "Variable number of tandem repeat of the $5^{\prime}$-flanking region of type-C human natriuretic peptide receptor gene influences blood pressure levels in obesity-associated hypertension," Hypertension Research, vol. 27, no. 10, pp. 711-716, 2004.

[4] K. Kosuge, M. Soma, T. Nakayama et al., "Human uncoupling protein 2 and 3 genes are associated with obesity in Japanese," Endocrine, vol. 34, no. 1-3, pp. 87-95, 2008.

[5] K. Strohacker and B. K. McFarlin, "Influence of obesity, physical inactivity, and weight cycling on chronic inflammation," Frontiers in Bioscience, vol. 2, pp. 98-104, 2010.

[6] K. J. Williams and I. Tabas, "The response-to-retention hypothesis of atherogenesis reinforced," Current Opinion in Lipidology, vol. 9, no. 5, pp. 471-474, 1998.

[7] K. J. Williams and I. Tabas, "Lipoprotein retention- and clues for atheroma regression," Arteriosclerosis, Thrombosis, and Vascular Biology, vol. 25, no. 8, pp. 1536-1540, 2005.

[8] Y. Zhang, R. Proenca, M. Maffei, M. Barone, L. Leopold, and J. M. Friedman, "Positional cloning of the mouse obese gene and its human homologue," Nature, vol. 372, no. 6505, pp. 425-432, 1994.

[9] A. D. Attie and P. E. Scherer, "Adipocyte metabolism and obesity," Journal of Lipid Research, vol. 50, supplement, pp. S395-S399, 2009.

[10] V. DeClercq, C. Taylor, and P. Zahradka, "Adipose tissue: the link between obesity and cardiovascular disease," Cardiovascular \& Hematological Disorders Drug Targets, vol. 8, no. 3, pp. 228-237, 2008.

[11] C. Fattah, N. Farah, S. Barry, N. O'Connor, B. Stuart, and M. J. Turner, "The measurement of maternal adiposity", Journal of Obstetrics and Gynaecology, vol. 29, no. 8, pp. 686-689, 2009.

[12] H. N. Sweeting, "Measurement and definitions of obesity in childhood and adolescence: a field guide for the uninitiated," Nutrition Journal, vol. 6, article 32, 2007. 
[13] M. Zamboni, E. Turcato, F. Armellini et al., "Sagittal abdominal diameter as a practical predictor of visceral fat," International Journal of Obesity, vol. 22, no. 7, pp. 655-660, 1998.

[14] H. S. Kahn, "Choosing an index for abdominal obesity: an opportunity for epidemiologic clarification," Journal of Clinical Epidemiology, vol. 46, no. 5, pp. 491-494, 1993.

[15] M. W. Rajala and P. E. Scherer, "Minireview: the adipocyteat the crossroads of energy homeostasis, inflammation, and atherosclerosis," Endocrinology, vol. 144, no. 9, pp. 37653773, 2003.

[16] A. Rodríguez, V. Catalán, J. Gómez-Ambrosi, and G. Frühbeck, "Visceral and subcutaneous adiposity: are both potential therapeutic targets for tackling the metabolic syndrome?" Current Pharmaceutical Design, vol. 13, no. 21, pp. 2169-2175, 2007.

[17] P. Bjorntorp, "The regulation of adipose tissue distribution in humans," International Journal of Obesity, vol. 20, no. 4, pp. 291-302, 1996.

[18] J. Stevens, E. G. Katz, and R. R. Huxley, "Associations between gender, age and waist circumference," European Journal of Clinical Nutrition, vol. 64, no. 1, pp. 6-15, 2010.

[19] E. B. Geer and W. Shen, "Gender differences in insulin resistance, body composition, and energy balance," Gender Medicine, vol. 6, no. 1, pp. 60-75, 2009.

[20] D. Canoy, "Distribution of body fat and risk of coronary heart disease in men and women," Current Opinion in Cardiology, vol. 23, no. 6, pp. 591-598, 2008.

[21] F. Samad, K. Yamamoto, M. Pandey, and D. J. Loskutoff, "Elevated expression of transforming growth factor- $\beta$ in adipose tissue from obese mice," Molecular Medicine, vol. 3, no. 1, pp. 37-48, 1997.

[22] S. K. Fried, D. A. Bunkin, and A. S. Greenberg, "Omental and subcutaneous adipose tissues of obese subjects release interleukin-6: depot difference and regulation by glucocorticoid," The Journal of Clinical Endocrinology \& Metabolism, vol. 83, no. 3, pp. 847-850, 1998.

[23] S. P. Weisberg, D. McCann, M. Desai, M. Rosenbaum, R. L. Leibel, and A. W. Ferrante Jr., "Obesity is associated with macrophage accumulation in adipose tissue," The Journal of Clinical Investigation, vol. 112, no. 12, pp. 1796-1808, 2003.

[24] S. Cinti, G. Mitchell, G. Barbatelli et al., "Adipocyte death defines macrophage localization and function in adipose tissue of obese mice and humans," Journal of Lipid Research, vol. 46, no. 11, pp. 2347-2355, 2005.

[25] M. K. Öhman, Y. Shen, C. I. Obimba et al., "Visceral adipose tissue inflammation accelerates atherosclerosis in apolipoprotein E-deficient mice," Circulation, vol. 117, no. 6, pp. 798-805, 2008.

[26] M. Tarakçioğlu, A. B. Erbağci, C. Usalan, R. Deveci, and R. Kocabaş, "Acute effect of hemodialysis on serum levels of the proinflammatory cytokines," Mediators of Inflammation, vol. 12, no. 1, pp. 15-19, 2003.

[27] T. P. Johnston, Y. Li, A. S. Jamal, D. J. Stechschulte, and K. N. Dileepan, "Poloxamer 407-induced atherosclerosis in mice appears to be due to lipid derangements and not due to its direct effects on endothelial cells and macrophages," Mediators of Inflammation, vol. 12, no. 3, pp. 147-155, 2003.

[28] C. Karlsson, K. Lindell, M. Ottosson, L. Sjöström, B. Carlsson, and L. M. S. Carlsson, "Human adipose tissue expresses angiotensinogen and enzymes required for its conversion to angiotensin II," The Journal of Clinical Endocrinology \& Metabolism, vol. 83, no. 11, pp. 3925-3929, 1998.
[29] G. Frühbeck, "The adipose tissue as a source of vasoactive factors," Current Medicinal Chemistry: Cardiovascular and Hematological Agents, vol. 2, no. 3, pp. 197-208, 2004.

[30] C. C. Wee, K. J. Mukamal, A. Huang, R. B. Davis, E. P. McCarthy, and M. A. Mittleman, "Obesity and C-reactive protein levels among white, black, and hispanic US adults," Obesity, vol. 16, no. 4, pp. 875-880, 2008.

[31] J. F. Keaney Jr., M. G. Larson, R. S. Vasan et al., "Obesity and systemic oxidative stress: clinical correlates of oxidative stress in the Framingham study," Arteriosclerosis, Thrombosis, and Vascular Biology, vol. 23, no. 3, pp. 434-439, 2003.

[32] M. Ryo, T. Nakamura, S. Kihara et al., "Adiponectin as a biomarker of the metabolic syndrome," Circulation Journal, vol. 68, no. 11, pp. 975-981, 2004.

[33] J. S. Yudkin, M. Kumari, S. E. Humphries, and V. MohamedAli, "Inflammation, obesity, stress and coronary heart disease: is interleukin-6 the link?" Atherosclerosis, vol. 148, no. 2, pp. 209-214, 2000.

[34] R. Hayaishi-Okano, Y. Yamasaki, N. Katakami et al., "Elevated C-reactive protein associates with early-stage carotid atherosclerosis in young subjects with type 1 diabetes," Diabetes Care, vol. 25, no. 8, pp. 1432-1438, 2002.

[35] V. Sigurdardottir, B. Fagerberg, and J. Hulthe, "Preclinical atherosclerosis and inflammation in 61-year-old men with newly diagnosed diabetes and established diabetes," Diabetes Care, vol. 27, no. 4, pp. 880-884, 2004.

[36] A. Saremi, R. J. Anderson, P. Luo et al., "Association between IL-6 and the extent of coronary atherosclerosis in the veterans affairs diabetes trial (VADT)," Atherosclerosis, vol. 203, no. 2, pp. 610-614, 2009.

[37] N. Katakami, H. Kaneto, M. Matsuhisa et al., "Association of soluble CD40 ligand with carotid atherosclerosis in Japanese type 1 diabetic patients," Diabetologia, vol. 49, no. 7, pp. 1670-1676, 2006.

[38] M. P. Reilly, N. Iqbal, M. Schutta et al., "Plasma leptin levels are associated with coronary atherosclerosis in type 2 diabetes," The Journal of Clinical Endocrinology \& Metabolism, vol. 89, no. 8, pp. 3872-3878, 2004.

[39] M. B. Pepys and G. M. Hirschfield, "C-reactive protein: a critical update," The Journal of Clinical Investigation, vol. 111, no. 12, pp. 1805-1812, 2003.

[40] P. M. van der Zee, E. Biró, L. A. Trouw et al., "Creactive protein in myocardial infarction binds to circulating microparticles but is not associated with complement activation," Clinical Immunology, vol. 135, no. 3, pp. 490-495, 2010.

[41] S. Kaptoge, E. D. Angelantonio, G. Lowe et al., "C-reactive protein concentration and risk of coronary heart disease, stroke, and mortality: an individual participant metaanalysis," The Lancet, vol. 375, no. 9709, pp. 132-140, 2010.

[42] Y. Momiyama, R. Ohmori, Z. A. Fayad et al., "Associations between plasma C-reactive protein levels and the severities of coronary and aortic atherosclerosis," Journal of Atherosclerosis and Thrombosis, vol. 17, no. 5, pp. 460-467, 2010.

[43] N. Ouchi, S. Kihara, T. Funahashi et al., "Reciprocal association of C-reactive protein with adiponectin in blood stream and adipose tissue," Circulation, vol. 107, no. 5, pp. 671-674, 2003.

[44] K. Esposito, A. Pontillo, C. Di Palo et al., "Effect of weight loss and lifestyle changes on vascular inflammatory markers in obese women: a randomized trial," Journal of the American Medical Association, vol. 289, no. 14, pp. 1799-1804, 2003. 
[45] K. Esposito, R. Marfella, M. Ciotola et al., "Effect of a Mediterranean-style diet on endothelial dysfunction and markers of vascular inflammation in the metabolic syndrome: a randomized trial," Journal of the American Medical Association, vol. 292, no. 12, pp. 1440-1446, 2004.

[46] K. Okita, H. Nishijima, T. Murakami et al., "Can exercise training with weight loss lower serum C-reactive protein levels?" Arteriosclerosis, Thrombosis, and Vascular Biology, vol. 24, no. 10, pp. 1868-1873, 2004.

[47] C. E. Donges, R. Duffield, and E. J. Drinkwater, "Effects of resistance or aerobic exercise training on interleukin-6, C-reactive protein, and body composition," Medicine and Science in Sports and Exercise, vol. 42, no. 2, pp. 304-313, 2010.

[48] J. J. Mann, J. R. Payne, T. Shah, D. J. Pennell, S. E. Humphries, and H. E. Montgomery, "C-reactive protein gene variant and the human left ventricular growth response to exercise: data from the LARGE heart study," Journal of Cardiovascular Pharmacology, vol. 55, no. 1, pp. 26-29, 2010.

[49] E. Malle and F. C. de Beer, "Human serum amyloid A (SAA) protein: a prominent acute-phase reactant for clinical practice," European Journal of Clinical Investigation, vol. 26, no. 6, pp. 427-435, 1996.

[50] C. Gabay and I. Kushner, "Acute-phase proteins and other systemic responses to inflammation," The New England Journal of Medicine, vol. 340, no. 6, pp. 448-454, 1999.

[51] T. Yamada, "Inflammatory markers; C-reactive protein (CRP) and serum amyloid A (SAA)," Rinsho Byori, vol. 53, no. 6, pp. 558-561, 2005.

[52] C. Poitou, N. Viguerie, R. Cancello et al., "Serum amyloid A: production by human white adipocyte and regulation by obesity and nutrition," Diabetologia, vol. 48, no. 3, pp. 519$528,2005$.

[53] R. Kisilevsky and S.-P. Tam, "Acute phase serum amyloid A, cholesterol metabolism, and cardiovascular disease," Pediatric Pathology \& Molecular Medicine, vol. 21, no. 3, pp. 291305, 2002.

[54] P. Libby and P. M. Ridker, "Novel inflammatory markers of coronary risk: theory versus practice," Circulation, vol. 100, no. 11, pp. 1148-1150, 1999.

[55] Y. Zhao, X. He, X. Shi et al., "Association between serum amyloid A and obesity: a meta-analysis and systematic review," Inflammation Research, vol. 59, no. 5, pp. 323-334, 2010.

[56] J. Danesh, J. Muir, Y.-K. Wong, M. Ward, J. R. Gallimore, and M. B. Pepys, "Risk factors for coronary heart disease and acute-phase proteins. A population-based study," European Heart Journal, vol. 20, no. 13, pp. 954-959, 1999.

[57] J. Jylhävä, A. Haarala, C. Eklund et al., "Serum amyloid A is independently associated with metabolic risk factors but not with early atherosclerosis: the Cardiovascular Risk in Young Finns Study," Journal of Internal Medicine, vol. 266, no. 3, pp. 286-295, 2009.

[58] J. Gómez-Ambrosi, C. Azcona, A. Patiño-García, and G. Frühbeck, "Serum amyloid A concentration is increased in obese children and adolescents," Journal of Pediatrics, vol. 153, no. 1, pp. 71-75, 2008.

[59] K. Kotani, N. Satoh, Y. Kato et al., "A novel oxidized low-density lipoprotein marker, serum amyloid A-LDL, is associated with obesity and the metabolic syndrome," Atherosclerosis, vol. 204, no. 2, pp. 526-531, 2009.
[60] B. D. Johnson, K. E. Kip, O. C. Marroquin et al., "Serum amyloid $\mathrm{A}$ as a predictor of coronary artery disease and cardiovascular outcome in women: the National Heart, Lung, and Blood Institute-Sponsored Women's Ischemia Syndrome Evaluation (WISE)," Circulation, vol. 109, no. 6, pp. 726-732, 2004.

[61] M. Kosuge, T. Ebina, T. Ishikawa et al., "Serum amyloid A is a better predictor of clinical outcomes than C-reactive protein in non-ST-segment elevation acute coronary syndromes," Circulation Journal, vol. 71, no. 2, pp. 186-190, 2007.

[62] P. M. Ridker, C. H. Hennekens, J. E. Buring, and N. Rifai, "C-reactive protein and other markers of inflammation in the prediction of cardiovascular disease in women," The New England Journal of Medicine, vol. 342, no. 12, pp. 836-843, 2000.

[63] E. Hatanaka, P. T. Monteagudo, M. S. M. Marrocos, and A. Campa, "Interaction between serum amyloid A and leukocytes-a possible role in the progression of vascular complications in diabetes," Immunology Letters, vol. 108, no. 2, pp. 160-166, 2007.

[64] R. Z. Yang, M. J. Lee, H. Hu et al., "Acute-phase serum amyloid A: an inflammatory adipokine and potential link between obesity and its metabolic complications," PLoS Medicine, vol. 3, no. 6, article e287, 2006.

[65] P. G. Wilson, J. C. Thompson, N. R. Webb, F. C. de Beer, V. L. King, and L. R. Tannock, "Serum amyloid A, but not Creactive protein, stimulates vascular proteoglycan synthesis in a pro-atherogenic manner," American Journal of Pathology, vol. 173, no. 6, pp. 1902-1910, 2008.

[66] C. Song, Y. Shen, E. Yamen et al., "Serum amyloid A may potentiate prothrombotic and proinflammatory events in acute coronary syndromes," Atherosclerosis, vol. 202, no. 2, pp. 596-604, 2009.

[67] C. Poitou, A. Divoux, A. Faty et al., "Role of serum amyloid A in adipocyte-macrophage cross talk and adipocyte cholesterol efflux," The Journal of Clinical Endocrinology \& Metabolism, vol. 94, no. 5, pp. 1810-1817, 2009.

[68] D. Brea, T. Sobrino, M. Blanco et al., "Usefulness of haptoglobin and serum amyloid A proteins as biomarkers for atherothrombotic ischemic stroke diagnosis confirmation," Atherosclerosis, vol. 205, no. 2, pp. 561-567, 2009.

[69] S. Uurtuya, K. Kotani, H. Koibuchi, N. Taniguchi, and T. Yamada, "Serum amyloid A protein and carotid intimamedia thickness in healthy young subjects," Journal of Atherosclerosis and Thrombosis, vol. 16, no. 3, pp. 299-300, 2009.

[70] C. L. Carty, P. Heagerty, S. R. Heckbert et al., "Association of genetic variation in serum amyloid-A with cardiovascular disease and interactions with IL6, IL1RN, IL1 ${ }^{2}$ and TNF genes in the Cardiovascular Health Study," Journal of Atherosclerosis and Thrombosis, vol. 16, no. 4, pp. 419-430, 2009.

[71] K. D. O'Brien and A. Chait, "Serum amyloid A: the "other" inflammatory protein," Current Atherosclerosis Reports, vol. 8, no. 1, pp. 62-68, 2006.

[72] S. H. Ley, S. B. Harris, P. W. Connelly et al., "Adipokines and incident type 2 diabetes in an aboriginal Canadian population: the Sandy Lake Health and Diabetes Project," Diabetes Care, vol. 31, no. 7, pp. 1410-1415, 2008.

[73] K. Samaras, N. K. Botelho, D. J. Chisholm, and R. V. Lord, "Subcutaneous and visceral adipose tissue gene expression of serum adipokines that predict type 2 diabetes," Obesity, vol. 18, no. 5, pp. 884-889, 2010. 
[74] X. Y. Ye, Y. M. Xue, J. P. Sha, C. Z. Li, and Z. J. Zhen, "Serum amyloid A attenuates cellular insulin sensitivity by increasing JNK activity in 3T3-L1 adipocytes," Journal of Endocrinological Investigation, vol. 32, no. 7, pp. 568-575, 2009.

[75] J. L. Halaas, K. S. Gajiwala, M. Maffei et al., "Weight-reducing effects of the plasma protein encoded by the obese gene," Science, vol. 269, no. 5223, pp. 543-546, 1995.

[76] M. K. Badman and J. S. Flier, "The adipocyte as an active participant in energy balance and metabolism," Gastroenterology, vol. 132, no. 6, pp. 2103-2115, 2007.

[77] K. Guo, J. E. McMinn, T. Ludwig et al., "Disruption of peripheral leptin signaling in mice results in hyperleptinemia without associated metabolic abnormalities," Endocrinology, vol. 148, no. 8, pp. 3987-3997, 2007.

[78] M. A. Pelleymounter, M. J. Cullen, M. B. Baker et al., "Effects of the obese gene product on body weight regulation in ob/ob mice," Science, vol. 269, no. 5223, pp. 540-543, 1995.

[79] I. S. Farooqi, G. Matarese, G. M. Lord et al., "Beneficial effects of leptin on obesity, T cell hyporesponsiveness, and neuroendocrine/metabolic dysfunction of human congenital leptin deficiency," The Journal of Clinical Investigation, vol. 110, no. 8, pp. 1093-1103, 2002.

[80] E. A. Oral, V. Simha, E. Ruiz et al., "Leptin-replacement therapy for lipodystrophy," The New England Journal of Medicine, vol. 346, no. 8, pp. 570-578, 2002.

[81] J. D. Luo, G. S. Zhang, and M. S. Chen, "Leptin and cardiovascular diseases," Timely Topic in Medicine, Cardiovascular Diseases, vol. 9, p. E34, 2005.

[82] M. W. Schwartz, S. C. Woods, D. Porte Jr., R. J. Seeley, and D. G. Baskin, "Central nervous system control of food intake," Nature, vol. 404, no. 6778, pp. 661-671, 2000.

[83] J. S. Flier, "Obesity wars: molecular progress confronts an expanding epidemic," Cell, vol. 116, no. 2, pp. 337-350, 2004.

[84] C. Buettner, E. D. Muse, A. Cheng et al., "Leptin controls adipose tissue lipogenesis via central, STAT3-independent mechanisms," Nature Medicine, vol. 14, no. 6, pp. 667-675, 2008.

[85] S. Blüher and C. S. Mantzoros, "Leptin in humans: lessons from translational research," American Journal of Clinical Nutrition, vol. 89, no. 3, pp. 991S-997S, 2009.

[86] L. Ozcan, A. S. Ergin, A. Lu et al., "Endoplasmic reticulum stress plays a central role in development of leptin resistance," Cell Metabolism, vol. 9, no. 1, pp. 35-51, 2009.

[87] M. Rosenbaum, M. Sy, K. Pavlovich, R. L. Leibel, and J. Hirsch, "Leptin reverses weight loss-induced changes in regional neural activity responses to visual food stimuli," The Journal of Clinical Investigation, vol. 118, no. 7, pp. 25832591, 2008.

[88] I. S. Farooqi, E. Bullmore, J. Keogh, J. Gillard, S. O’Rahilly, and P. C. Fletcher, "Leptin regulates striatal regions and human eating behavior," Science, vol. 317, no. 5843, p. 1355, 2007.

[89] R. S. Ahima, "Revisiting leptin's role in obesity and weight loss," The Journal of Clinical Investigation, vol. 118, no. 7, pp. 2380-2383, 2008.

[90] G. Sweeney, "Cardiovascular effects of leptin," Nature Reviews Cardiology, vol. 7, no. 1, pp. 22-29, 2010.

[91] A. M. Brennan, T. Y. Li, I. Kelesidis, A. Gavrila, F. B. Hu, and C. S. Mantzoros, "Circulating leptin levels are not associated with cardiovascular morbidity and mortality in women with diabetes: a prospective cohort study," Diabetologia, vol. 50, no. 6, pp. 1178-1185, 2007.
[92] P. Welsh, H. M. Murray, B. M. Buckley et al., "Leptin predicts diabetes but not cardiovascular disease: results from a large prospective study in an elderly population," Diabetes Care, vol. 32, no. 2, pp. 308-310, 2009.

[93] M. Karakas, A. Zierer, C. Herder et al., "Leptin, adiponectin, their ratio and risk of coronary heart disease: results from the MONICA/KORA Augsburg Study 1984-2002," Atherosclerosis, vol. 209, no. 1, pp. 220-225, 2010.

[94] P. Singh, T. E. Peterson, K. R. Barber et al., "Leptin upregulates the expression of plasminogen activator inhibitor- 1 in human vascular endothelial cells," Biochemical and Biophysical Research Communications, vol. 392, no. 1, pp. 47-52, 2010.

[95] S. Hongo, T. Watanabe, S. Arita et al., "Leptin modulates ACAT1 expression and cholesterol efflux from human macrophages," American Journal of Physiology, vol. 297, no. 2, pp. E474-E482, 2009.

[96] C. Vecchione, A. Maffei, S. Colella et al., "Leptin effect on endothelial nitric oxide is mediated through Akt-endothelial nitric oxide synthase phosphorylation pathway," Diabetes, vol. 51, no. 1, pp. 168-173, 2002.

[97] A. Rodríguez, A. Fortuño, J. Gómez-Ambrosi, G. Zalba, J. Díez, and G. Frühbeck, "The inhibitory effect of leptin on angiotensin II-induced vasoconstriction in vascular smooth muscle cells is mediated via a nitric oxide-dependent mechanism," Endocrinology, vol. 148, no. 1, pp. 324-331, 2007.

[98] B. Bigalke, K. Stellos, T. Geisler, P. Seizer, V. Mozes, and M. Gawaz, "High plasma levels of adipocytokines are associated with platelet activation in patients with coronary artery disease," Platelets, vol. 21, no. 1, pp. 11-19, 2010.

[99] A. A. Fisher, S. L. Goh, W. Srikusalankul, E. N. Southcott, and M. W. Davis, "Serum leptin levels in older patients with hip fracture-impact on peri-operative myocardial injury," The American Heart Hospital Journal, vol. 7, no. 1, pp. 9-16, 2009.

[100] K. R. Mcgaffin, B. Zou, C. F. McTiernan, and C. P. O’Donnell, "Leptin attenuates cardiac apoptosis after chronic ischaemic injury," Cardiovascular Research, vol. 83, no. 2, pp. 313-324, 2009.

[101] A. Schober and C. Weber, "Editorial: leptin and EPCs in arterial injury: yes, we can!," Circulation Research, vol. 103, no. 5, pp. 447-449, 2008.

[102] A. H. Hasty, H. Shimano, J.-I. Osuga et al., "Severe hypercholesterolemia, hypertriglyceridemia, and atherosclerosis in mice lacking both leptin and the low density lipoprotein receptor," The Journal of Biological Chemistry, vol. 276, no. 40, pp. 37402-37408, 2001.

[103] A. M. Wallace, A. D. McMahon, C. J. Packard et al., "Plasma leptin and the risk of cardiovascular disease in the west of Scotland coronary prevention study (WOSCOPS)," Circulation, vol. 104, no. 25, pp. 3052-3056, 2001.

[104] Y. Matsuzawa, T. Funahashi, S. Kihara, and I. Shimomura, "Adiponectin and metabolic syndrome," Arteriosclerosis, Thrombosis, and Vascular Biology, vol. 24, no. 1, pp. 29-33, 2004.

[105] T. Bobbert, H. Rochlitz, U. Wegewitz et al., "Changes of adiponectin oligomer composition by moderate weight reduction," Diabetes, vol. 54, no. 9, pp. 2712-2719, 2005.

[106] J. Capeau, "The story of adiponectin and its receptors AdipoR1 and R2: to follow," Journal of Hepatology, vol. 47, no. 5, pp. 736-738, 2007.

[107] T. Yamauchi, Y. Nio, T. Maki et al., "Targeted disruption of AdipoR1 and AdipoR2 causes abrogation of adiponectin binding and metabolic actions," Nature Medicine, vol. 13, no. 3, pp. 332-339, 2007. 
[108] T. Hansen, H. Ahlström, S. Söderberg et al., "Visceral adipose tissue, adiponectin levels and insulin resistance are related to atherosclerosis as assessed by whole-body magnetic resonance angiography in an elderly population," Atherosclerosis, vol. 205, no. 1, pp. 163-167, 2009.

[109] H. Tilg and G. S. Hotamisligil, "Nonalcoholic fatty liver disease: cytokine-adipokine interplay and regulation of insulin resistance," Gastroenterology, vol. 131, no. 3, pp. 934-945, 2006.

[110] A. Stofkova, "Leptin and adiponectin: from energy and metabolic dysbalance to inflammation and autoimmunity," Endocrine Regulations, vol. 43, no. 4, pp. 157-168, 2009.

[111] I. B. Bauche, S. A. El Mkadem, A.-M. Pottier et al., "Overexpression of adiponectin targeted to adipose tissue in transgenic mice: impaired adipocyte differentiation," Endocrinology, vol. 148, no. 4, pp. 1539-1549, 2007.

[112] S. Otabe, X. Yuan, T. Fukutani et al., "Overexpression of human adiponectin in transgenic mice results in suppression of fat accumulation and prevention of premature death by high-calorie diet," American Journal of Physiology, vol. 293, no. 1, pp. E210-E218, 2007.

[113] L. Qiao, C. Zou, D. R. van der Westhuyzen, and J. Shao, "Adiponectin reduces plasma triglyceride by increasing VLDL triglyceride catabolism," Diabetes, vol. 57, no. 7, pp. 1824-1833, 2008.

[114] G. Deng, Y. Long, Y.-R. Yu, and M.-R. Li, "Adiponectin directly improves endothelial dysfunction in obese rats through the AMPK-eNOS Pathway," International Journal of Obesity, vol. 34, no. 1, pp. 165-171, 2010.

[115] J. Ran, X. Xiong, W. Liu et al., "Increased plasma adiponectin closely associates with vascular endothelial dysfunction in type 2 diabetic patients with diabetic nephropathy," Diabetes Research and Clinical Practice, vol. 88, no. 2, pp. 177-183, 2010.

[116] A. S. Peña, D. P. Belobrajdic, E. Wiltshire, R. Gent, C. Hirte, and J. Couper, "Adiponectin relates to smooth muscle function and folate in obese children," International Journal of Pediatric Obesity, vol. 5, no. 2, pp. 185-191, 2010.

[117] K. Ohashi, J. L. Parker, N. Ouchi et al., "Adiponectin promotes macrophage polarization toward an anti-inflammatory phenotype," The Journal of Biological Chemistry, vol. 285, no. 9, pp. 6153-6160, 2010.

[118] N. Ouchi and K. Walsh, "Adiponectin as an antiinflammatory factor," Clinica Chimica Acta, vol. 380, no. 1-2, pp. 24-30, 2007.

[119] V. Beauloye, F. Zech, H. T. T. Mong, P. Clapuyt, M. Maes, and S. M. Brichard, "Determinants of early atherosclerosis in obese children and adolescents," The Journal of Clinical Endocrinology \& Metabolism, vol. 92, no. 8, pp. 3025-3032, 2007.

[120] N. Sattar, G. Wannamethee, N. Sarwar et al., "Adiponectin and coronary heart disease: a prospective study and meta-analysis," Circulation, vol. 114, no. 7, pp. 623-629, 2006.

[121] R. Ouedraogo, Y. Gong, B. Berzins et al., "Adiponectin deficiency increases leukocyte-endothelium interactions via upregulation of endothelial cell adhesion molecules in vivo," The Journal of Clinical Investigation, vol. 117, no. 6, pp. 1718-1726, 2007.

[122] D. M. Maahs, L. G. Ogden, G. L. Kinney et al., "Low plasma adiponectin levels predict progression of coronary artery calcification," Circulation, vol. 111, no. 6, pp. 747-753, 2005.
[123] J. L. Fargnoli, Q. Sun, D. Olenczuk et al., "Resistin is associated with biomarkers of inflammation while total and high-molecular weight adiponectin are associated with biomarkers of inflammation, insulin resistance, and endothelial function," European Journal of Endocrinology, vol. 162, no. 2, pp. 281-288, 2010.

[124] P. Calabro, D. W. Chang, J. T. Willerson, and E. T. H. Yeh, "Release of C-reactive protein in response to inflammatory cytokines by human adipocytes: linking obesity to vascular inflammation," Journal of the American College of Cardiology, vol. 46, no. 6, pp. 1112-1113, 2005.

[125] C. M. Steppan, S. T. Bailey, S. Bhat et al., "The hormone resistin links obesity to diabetes," Nature, vol. 409, no. 6818, pp. 307-312, 2001.

[126] A. M. Kunnari, E.-R. Savolainen, O. H. Ukkola, Y. A. Kesäniemi, and M. A. Jokela, "The expression of human resistin in different leucocyte lineages is modulated by LPS and TNF $\alpha$," Regulatory Peptides, vol. 157, no. 1-3, pp. 57-63, 2009.

[127] I. Manduteanu, M. Pirvulescu, A. M. Gan et al., "Similar effects of resistin and high glucose on P-selectin and fractalkine expression and monocyte adhesion in human endothelial cells," Biochemical and Biophysical Research Communications, vol. 391, no. 3, pp. 1443-1448, 2010.

[128] R.-Z. Yang, Q. Huang, A. Xu et al., "Comparative studies of resistin expression and phylogenomics in human and mouse," Biochemical and Biophysical Research Communications, vol. 310, no. 3, pp. 927-935, 2003.

[129] S. Verma, S.-H. Li, C.-H. Wang et al., "Resistin promotes endothelial cell activation: further evidence of adipokineendothelial interaction," Circulation, vol. 108, no. 6, pp. 736-740, 2003.

[130] P. Calabro, I. Samudio, J. T. Willerson, and E. T. H. Yeh, "Resistin promotes smooth muscle cell proliferation through activation of extracellular signal-regulated kinase $1 / 2$ and phosphatidylinositol 3-kinase pathways," Circulation, vol. 110, no. 21, pp. 3335-3340, 2004.

[131] R. R. Banerjee, S. M. Rangwala, J. S. Shapiro et al., "Regulation of fasted blood glucose by resistin," Science, vol. 303, no. 5661, pp. 1195-1198, 2004.

[132] C. L. McTernan, P. G. McTernan, A. L. Harte, P. L. Levick, A. H. Barnett, and S. Kumar, "Resistin, central obesity, and type 2 diabetes," Lancet, vol. 359, no. 9300, pp. 46-47, 2002.

[133] M. Li, A. Fisette, X.-Y. Zhao, J.-Y. Deng, J. Mi, and K. Cianflone, "Serum resistin correlates with central obesity but weakly with insulin resistance in Chinese children and adolescents," International Journal of Obesity, vol. 33, no. 4, pp. 424-439, 2009.

[134] A. Haseeb, M. Iliyas, S. Chakrabarti et al., "Single-nucleotide polymorphisms in peroxisome proliferator-activated receptor gamma and their association with plasma levels of resistin and the metabolic syndrome in a South Indian population," Journal of Biosciences, vol. 34, no. 3, pp. 405-414, 2009.

[135] H. Asano, H. Izawa, K. Nagata et al., "Plasma resistin concentration determined by common variants in the resistin gene and associated with metabolic traits in an aged Japanese population," Diabetologia, vol. 53, no. 2, pp. 234-246, 2010.

[136] J. H. Lee, J. W. Bullen Jr., V. L. Stoyneva, and C. S. Mantzoros, "Circulating resistin in lean, obese, and insulin-resistant mouse models: lack of association with insulinemia and glycemia," American Journal of Physiology, vol. 288, no. 3, pp. E625-E632, 2005. 
[137] G. Valsamakis, P. G. McTernan, R. Chetty et al., "Modest weight loss and reduction in waist circumference after medical treatment are associated with favorable changes in serum adipocytokines," Metabolism: Clinical and Experimental, vol. 53, no. 4, pp. 430-434, 2004.

[138] J. Vendrell, M. Broch, N. Vilarrasa et al., "Resistin, adiponectin, ghrelin, leptin, and proinflammatory cytokines: relationships in obesity," Obesity Research, vol. 12, no. 6, pp. 962-971, 2004.

[139] B. Samal, Y. Sun, G. Stearns, C. Xie, S. Suggs, and I. McNiece, "Cloning and characterization of the cDNA encoding a novel human pre-B-cell colony-enhancing factor," Molecular and Cellular Biology, vol. 14, no. 2, pp. 1431-1437, 1994.

[140] A. Fukuhara, M. Matsuda, M. Nishizawa et al., "Visfatin: a protein secreted by visceral fat that mimics the effects of insulin," Science, vol. 307, no. 5708, pp. 426-430, 2005.

[141] J. R. Revollo, A. Körner, K. F. Mills et al., "Nampt/PBEF/visfatin regulates insulin secretion in $\beta$ cells as a systemic NAD biosynthetic enzyme," Cell Metabolism, vol. 6, no. 5, pp. 363-375, 2007.

[142] A. Fukuhara, M. Matsuda, M. Nishizawa et al., "Retraction," Science, vol. 318, no. 5850, p. 565, 2007.

[143] S. H. Jia, Y. Li, J. Parodo et al., "Pre-B cell colony-enhancing factor inhibits neutrophil apoptosis in experimental inflammation and clinical sepsis," The Journal of Clinical Investigation, vol. 113, no. 9, pp. 1318-1327, 2004.

[144] A. R. Moschen, A. Kaser, B. Enrich et al., "Visfatin, an adipocytokine with proinflammatory and immunomodulating properties," Journal of Immunology, vol. 178, no. 3, pp. 1748-1758, 2007.

[145] S. Kralisch, J. Klein, U. Lossner et al., "Hormonal regulation of the novel adipocytokine visfatin in 3T3-L1 adipocytes," Journal of Endocrinology, vol. 185, no. 3, pp. R1-R8, 2005.

[146] K. C. Choi, O. H. Ryu, K. W. Lee et al., "Effect of PPAR- \pm and $-^{3}$ agonist on the expression of visfatin, adiponectin, and TNF- \pm in visceral fat of OLETF rats," Biochemical and Biophysical Research Communications, vol. 336, no. 3, pp. 747-753, 2005.

[147] M. Hallschmid, H. Randeva, B. K. Tan, W. Kern, and H. Lehnert, "Relationship between cerebrospinal fluid visfatin (PBEF/Nampt) levels and adiposity in humans," Diabetes, vol. 58, no. 3, pp. 637-640, 2009.

[148] N. Rasouli and P. A. Kern, "Adipocytokines and the metabolic complications of obesity," The Journal of Clinical Endocrinology \& Metabolism, vol. 93, no. 11, supplement 1, pp. s64-s73, 2008.

[149] M. Laudes, F. Oberhauser, D. M. Schulte et al., "Visfatin/PBEF/Nampt and resistin expressions in circulating blood monocytes are differentially related to obesity and type 2 diabetes in humans," Hormone and Metabolic Research, vol. 42, no. 4, pp. 268-273, 2010.

[150] S.-I. Imai, "Nicotinamide phosphoribosyltransferase (Nampt): a link between NAD biology, metabolism, and diseases," Current Pharmaceutical Design, vol. 15, no. 1, pp. 20-28, 2009.

[151] V. Varma, A. Yao-Borengasser, N. Rasouli et al., "Human visfatin expression: relationship to insulin sensitivity, intramyocellular lipids, and inflammation," The Journal of Clinical Endocrinology \& Metabolism, vol. 92, no. 2, pp. 666-672, 2007.

[152] J. Berndt, N. Klöting, S. Kralisch et al., "Plasma visfatin concentrations and fat depot-specific mRNA expression in humans," Diabetes, vol. 54, no. 10, pp. 2911-2916, 2005.
[153] S. W. Liu, S. B. Qiao, J. S. Yuan, and D. Q. Liu, "Association of plasma visfatin levels with inflammation, atherosclerosis and acute coronary syndromes (ACS) in humans," Clinical Endocrinology, vol. 71, no. 2, pp. 202-207, 2009.

[154] M. Davutoglu, M. Ozkaya, E. Guler et al., "Plasma visfatin concentrations in childhood obesity: relationships to insulin resistance and anthropometric indices," Swiss Medical Weekly, vol. 139, no. 1-2, pp. 22-27, 2009.

[155] Y. Liang, X. M. Xu, H. S. Wang, and P. W. Wang, "Correlation between the expression of gastrocolic omentum visfatin mRNA and gestational diabetes mellitus," Zhonghua Fu Chan Ke Za Zhi, vol. 43, no. 11, pp. 824-827, 2008.

[156] A. I. F. Blakemore, D. Meyre, J. Delplanque et al., "A rare variant in the visfatin gene (NAMPT/PBEF1) is associated with protection from obesity," Obesity, vol. 17, no. 8, pp. 1549-1553, 2009.

[157] V. Catalán, J. Gómez-Ambrosi, A. Rodríguez et al., "Association of increased Visfatin/PBEF/NAMPT circulating concentrations and gene expression levels in peripheral blood cells with lipid metabolism and fatty liver in human morbid obesity," Nutrition, Metabolism and Cardiovascular Diseases. In press.

[158] A. Stofkova, "Resistin and visfatin: regulators of insulin sensitivity, inflammation and immunity," Endocrine Regulations, vol. 44, no. 1, pp. 25-36, 2010.

[159] T. B. Dahl, A. Yndestad, M. Skjelland et al., "Increased expression of visfatin in macrophages of human unstable carotid and coronary atherosclerosis: possible role in inflammation and plaque destabilization," Circulation, vol. 115, no. 8, pp. 972-980, 2007.

[160] K. Takebayashi, M. Suetsugu, S. Wakabayashi, Y. Aso, and T. Inukai, "Association between plasma visfatin and vascular endothelial function in patients with type 2 diabetes mellitus," Metabolism: Clinical and Experimental, vol. 56, no. 4, pp. 451-458, 2007.

[161] A. Garten, S. Petzold, A. Körner, S.-I. Imai, and W. Kiess, "Nampt: linking NAD biology, metabolism and cancer," Trends in Endocrinology and Metabolism, vol. 20, no. 3, pp. 130-138, 2009.

[162] T.-F. Chan, Y.-L. Chen, C.-H. Lee et al., "Decreased plasma visfatin concentrations in women with gestational diabetes mellitus," Journal of the Society for Gynecologic Investigation, vol. 13, no. 5, pp. 364-367, 2006.

[163] M.-P. Chen, F.-M. Chung, D.-M. Chang et al., "Elevated plasma level of visfatin/pre-B cell colony-enhancing factor in patients with type 2 diabetes mellitus," The Journal of Clinical Endocrinology \& Metabolism, vol. 91, no. 1, pp. 295-299, 2006.

[164] D. G. Haider, J. Pleiner, M. Francesconi, G. F. Wiesinger, M. Müller, and M. Wolzt, "Exercise training lowers plasma visfatin concentrations in patients with type 1 diabetes," The Journal of Clinical Endocrinology \& Metabolism, vol. 91, no. 11, pp. 4702-4704, 2006.

[165] S.-G. Roh, S.-H. Song, K.-C. Choi et al., "Chemerin-a new adipokine that modulates adipogenesis via its own receptor," Biochemical and Biophysical Research Communications, vol. 362, no. 4, pp. 1013-1018, 2007.

[166] V. Wittamer, B. Bondue, A. Guillabert, G. Vassart, M. Parmentier, and D. Communi, "Neutrophil-mediated maturation of chemerin: a link between innate and adaptive immunity," Journal of Immunology, vol. 175, no. 1, pp. 487-493, 2005. 
[167] S. Parolini, A. Santoro, E. Marcenaro et al., "The role of chemerin in the colocalization of NK and dendritic cell subsets into inflamed tissues," Blood, vol. 109, no. 9, pp. 3625-3632, 2007.

[168] M. Lehrke, A. Becker, M. Greif et al., "Chemerin is associated with markers of inflammation and components of the metabolic syndrome but does not predict coronary atherosclerosis," European Journal of Endocrinology, vol. 161, no. 2, pp. 339-344, 2009.

[169] L. Y. Wang, L. Wei, H. Y. Yu, Y. Zhang, and W. P. Jia, "Relationship of serum Chemerin to obesity and type 2 diabetes mellitus," Zhonghua Yi Xue Za Zhi, vol. 89, no. 4, pp. 235-238, 2009.

[170] D. Stejskal, M. Karpisek, Z. Hanulova, and M. Svestak, "Chemerin is an independent marker of the metabolic syndrome in a Caucasian population-a pilot study," Biomedical Papers of the Medical Faculty of the University Palacký, Olomouc, Czechoslovakia, vol. 152, no. 2, pp. 217-221, 2008.

[171] X.-Y. Du, B. A. Zabel, T. Myles et al., "Regulation of chemerin bioactivity by plasma carboxypeptidase $\mathrm{N}$, carboxypeptidase $\mathrm{B}$ (activated thrombin-activable fibrinolysis inhibitor), and platelets," The Journal of Biological Chemistry, vol. 284, no. 2, pp. 751-758, 2009.

[172] K. B. Goralski, T. C. McCarthy, E. A. Hanniman et al., "Chemerin, a novel adipokine that regulates adipogenesis and adipocyte metabolism," The Journal of Biological Chemistry, vol. 282, no. 38, pp. 28175-28188, 2007.

[173] C. Albanesi, C. Scarponi, S. Pallotta et al., "Chemerin expression marks early psoriatic skin lesions and correlates with plasmacytoid dendritic cell recruitment," The Journal of Experimental Medicine, vol. 206, no. 1, pp. 249-258, 2009.

[174] V. Wittamer, J.-D. Franssen, M. Vulcano et al., "Specific recruitment of antigen-presenting cells by chemerin, a novel processed ligand from human inflammatory fluids," The Journal of Experimental Medicine, vol. 198, no. 7, pp. 977-985, 2003.

[175] H. John, J. Hierer, O. Haas, and W.-G. Forssmann, "Quantification of angiotensin-converting-enzymemediated degradation of human chemerin 145-154 in plasma by matrix-assisted laser desorption/ionization-timeof-flight mass spectrometry," Analytical Biochemistry, vol. 362, no. 1, pp. 117-125, 2007.

[176] A. Guillabert, V. Wittamer, B. Bondue et al., "Role of neutrophil proteinase 3 and mast cell chymase in chemerin proteolytic regulation," Journal of Leukocyte Biology, vol. 84, no. 6, pp. 1530-1539, 2008.

[177] J. L. Cash, R. Hart, A. Russ et al., "Synthetic chemerinderived peptides suppress inflammation through ChemR23," The Journal of Experimental Medicine, vol. 205, no. 4, pp. 767-775, 2008.

[178] M. Takahashi, Y. Takahashi, K. Takahashi et al., "Chemerin enhances insulin signaling and potentiates insulin-stimulated glucose uptake in 3T3-L1 adipocytes," FEBS Letters, vol. 582, no. 5, pp. 573-578, 2008.

[179] K. Bozaoglu, K. Bolton, J. McMillan et al., "Chemerin is a novel adipokine associated with obesity and metabolic syndrome," Endocrinology, vol. 148, no. 10, pp. 4687-4694, 2007.

[180] L. Fontana, J. C. Eagon, M. E. Trujillo, P. E. Scherer, and S. Klein, "Visceral fat adipokine secretion is associated with systemic inflammation in obese humans," Diabetes, vol. 56, no. 4, pp. 1010-1013, 2007.
[181] T. Komiya, Y. Tanigawa, and S. Hirohashi, "Cloning of the novel gene intelectin, which is expressed in intestinal paneth cells in mice," Biochemical and Biophysical Research Communications, vol. 251, no. 3, pp. 759-762, 1998.

[182] R.-Z. Yang, M.-J. Lee, H. Hu et al., "Identification of omentin as a novel depot-specific adipokine in human adipose tissue: possible role in modulating insulin action," American Journal of Physiology, vol. 290, no. 6, pp. E1253-E1261, 2006.

[183] A. Schäffler, M. Neumeier, H. Herfarth, A. Fürst, J. Schölmerich, and C. Büchler, "Genomic structure of human omentin, a new adipocytokine expressed in omental adipose tissue," Biochimica et Biophysica Acta, vol. 1732, no. 1-3, pp. 96-102, 2005.

[184] H.-Y. Pan, L. Guo, and Q. Li, "Changes of serum omentin-1 levels in normal subjects and in patients with impaired glucose regulation and with newly diagnosed and untreated type 2 diabetes," Diabetes Research and Clinical Practice, vol. 88, no. 1, pp. 29-33, 2010.

[185] C. M. de Souza Batista, R.-Z. Yang, M.-J. Lee et al., "Omentin plasma levels and gene expression are decreased in obesity," Diabetes, vol. 56, no. 6, pp. 1655-1661, 2007.

[186] B. K. Tan, R. Adya, S. Farhatullah et al., "Omentin-1, a novel adipokine, is decreased in overweight insulin-resistant women with polycystic ovary syndrome ex vivo in vivo regulation of omentin-1 by insulin and glucose," Diabetes, vol. 57, no. 4, pp. 801-808, 2008.

[187] D. K. Lee, S. R. George, and B. F. O’Dowd, "Unravelling the roles of the apelin system: prospective therapeutic applications in heart failure and obesity," Trends in Pharmacological Sciences, vol. 27, no. 4, pp. 190-194, 2006.

[188] Y. Iwanaga, Y. Kihara, H. Takenaka, and T. Kita, "Downregulation of cardiac apelin system in hypertrophied and failing hearts: possible role of angiotensin II-angiotensin type 1 receptor system," Journal of Molecular and Cellular Cardiology, vol. 41, no. 5, pp. 798-806, 2006.

[189] V.-P. Ronkainen, J. J. Ronkainen, S. L. Hänninen et al., "Hypoxia inducible factor regulates the cardiac expression and secretion of apelin," The FASEB Journal, vol. 21, no. 8, pp. 1821-1830, 2007.

[190] P. Atluri, K. J. Morine, G. P. Liao et al., "Ischemic heart failure enhances endogenous myocardial apelin and APJ receptor expression," Cellular \& Molecular Biology Letters, vol. 12, no. 1, pp. 127-138, 2007.

[191] J. Zhang, C. X. Ren, Y. F. Qi et al., "Exercise training promotes expression of apelin and APJ of cardiovascular tissues in spontaneously hypertensive rats," Life Sciences, vol. 79, no. 12, pp. 1153-1159, 2006.

[192] K. Higuchi, T. Masaki, K. Gotoh et al., "Apelin, an APJ receptor ligand, regulates body adiposity and favors the messenger ribonucleic acid expression of uncoupling proteins in mice," Endocrinology, vol. 148, no. 6, pp. 2690-2697, 2007.

[193] Z. Zhang, B. Yu, and G.-Z. Tao, "Apelin protects against cardiomyocyte apoptosis induced by glucose deprivation," Chinese Medical Journal, vol. 122, no. 19, pp. 2360-2365, 2009.

[194] B. Telejko, M. Kuzmicki, N. Wawrusiewicz-Kurylonek et al., "Plasma apelin levels and apelin/APJ mRNA expression in patients with gestational diabetes mellitus," Diabetes Research and Clinical Practice, vol. 87, no. 2, pp. 176-183, 2010.

[195] P. T. Ellinor, A. F. Low, and C. A. MacRae, "Reduced apelin levels in lone atrial fibrillation," European Heart Journal, vol. 27, no. 2, pp. 222-226, 2006. 
[196] K. S. Chong, R. S. Gardner, J. J. Morton, E. A. Ashley, and T. A. McDonagh, "Plasma concentrations of the novel peptide apelin are decreased in patients with chronic heart failure," European Journal of Heart Failure, vol. 8, no. 4, pp. 355-360, 2006.

[197] P. Francia, A. Salvati, C. Balla et al., "Cardiac resynchronization therapy increases plasma levels of the endogenous inotrope apelin," European Journal of Heart Failure, vol. 9, no. 3, pp. 306-309, 2007.

[198] K. Hida, J. Wada, J. Eguchi et al., "Visceral adipose tissue-derived serine protease inhibitor: a unique insulinsensitizing adipocytokine in obesity," Proceedings of the National Academy of Sciences of the United States of America, vol. 102, no. 30, pp. 10610-10615, 2005.

[199] K. Kawano, T. Hirashima, S. Mori, Y. Saitoh, M. Kurosumi, and T. Natori, "Spontaneous long-term hyperglycemic rat with diabetic complications: Otsuka Long-Evans Tokushima Fatty (OLETF) strain," Diabetes, vol. 41, no. 11, pp. 1422$1428,1992$.

[200] N. Klöting, J. Berndt, S. Kralisch et al., "Vaspin gene expression in human adipose tissue: association with obesity and type 2 diabetes," Biochemical and Biophysical Research Communications, vol. 339, no. 1, pp. 430-436, 2006.

[201] J.-K. Cho, T.-K. Han, and H.-S. Kang, "Combined effects of body mass index and cardio/respiratory fitness on serum vaspin concentrations in Korean young men," European Journal of Applied Physiology, vol. 108, no. 2, pp. 347-353, 2010.

[202] B.-S. Youn, N. Klöting, J. Kratzsch et al., "Serum vaspin concentrations in human obesity and type 2 diabetes," Diabetes, vol. 57, no. 2, pp. 372-377, 2008.

[203] Y. Ye, X.-H. Hou, X.-P. Pan, J.-X. Lu, and W.-P. Jia, "Serum vaspin level in relation to postprandial plasma glucose concentration in subjects with diabetes," Chinese Medical Journal, vol. 122, no. 21, pp. 2530-2533, 2009.

[204] Q. Yang, T. E. Graham, N. Mody et al., "Serum retinol binding protein 4 contributes to insulin resistance in obesity and type 2 diabetes," Nature, vol. 436, no. 7049, pp. 356-362, 2005.

[205] N. Mody, T. E. Graham, Y. Tsuji, Q. Yang, and B. B. Kahn, "Decreased clearance of serum retinol-binding protein and elevated levels of transthyretin in insulin-resistant ob/ob mice," American Journal of Physiology, vol. 294, no. 4, pp. E785-E793, 2008.

[206] L. Munkhtulga, S. Nagashima, K. Nakayama et al., "Regulatory SNP in the RBP4 gene modified the expression in adipocytes and associated with BMI," Obesity, vol. 18, no. 5, pp. 1006-1014, 2010.

[207] J.-B. Suh, S.-M. Kim, G.-J. Cho, K.-M. Choi, J.-H. Han, and $\mathrm{H}$. Taek Geun, "Elevated serum retinol-binding protein 4 is associated with insulin resistance in older women," Metabolism: Clinical and Experimental, vol. 59, no. 1, pp. 118-122, 2010.

[208] C. An, H. Wang, X. Liu et al., "Serum retinol-binding protein 4 is elevated and positively associated with insulin resistance in postmenopausal women," Endocrine Journal, vol. 56, no. 8, pp. 987-996, 2009.

[209] K. Klein, D. Bancher-Todesca, H. Leipold et al., "Retinolbinding protein 4 in patients with gestational diabetes mellitus," Journal of Women's Health, vol. 19, no. 3, pp. 517-521, 2010.

[210] S. Gao, M. Li, Z. Wang et al., "Serum levels of retinol-binding protein-4 and its association with metabolic syndrome in first-degree relatives of type 2 diabetes mellitus," Zhonghua Yi Xue Za Zhi, vol. 89, no. 30, pp. 2129-2133, 2009.
[211] C.-C. Lin, M.-M. Lai, T.-C. Li et al., "Relationship between serum retinol-binding protein 4 and visfatin and the metabolic syndrome," Diabetes Research and Clinical Practice, vol. 85, no. 1, pp. 24-29, 2009.

[212] N. Santoro, L. Perrone, G. Cirillo et al., "Variations of retinol binding protein 4 levels are not associated with changes in insulin resistance during puberty," Journal of Endocrinological Investigation, vol. 32, no. 5, pp. 411-414, 2009.

[213] N. M. Al-Daghri, O. S. Al-Attas, M. Alokail, H. M. Draz, A. Bamakhramah, and S. Sabico, "Retinol binding protein-4 is associated with TNF- $\alpha$ and not insulin resistance in subjects with type 2 diabetes mellitus and coronary heart disease," Disease Markers, vol. 26, no. 3, pp. 135-140, 2009.

[214] P. Bobbert, A. Weithäuser, J. Andres et al., "Increased plasma retinol binding protein 4 levels in patients with inflammatory cardiomyopathy," European Journal of Heart Failure, vol. 11, no. 12, pp. 1163-1168, 2009.

[215] M. Sasaki, T. Otani, M. Kawakami, and S.-E. Ishikawa, "Elevation of plasma retinol-binding protein 4 and reduction of plasma adiponectin in subjects with cerebral infarction," Metabolism: Clinical and Experimental, vol. 59, no. 4, pp. 527-532, 2010. 


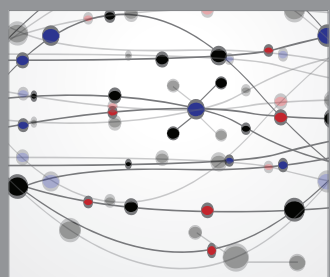

The Scientific World Journal
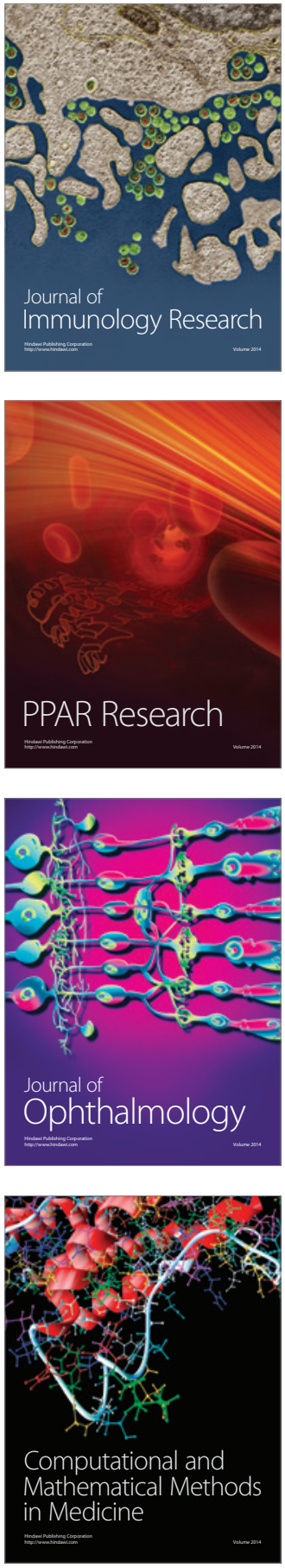

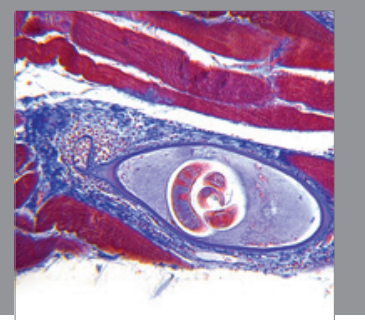

Gastroenterology

Research and Practice
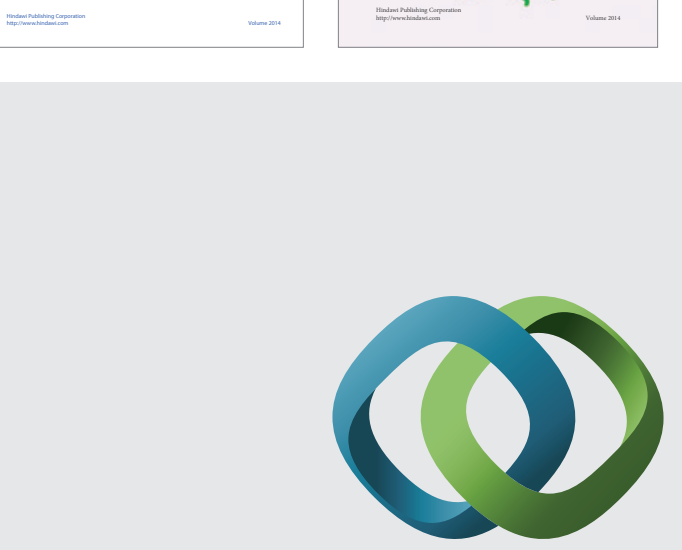

\section{Hindawi}

Submit your manuscripts at

http://www.hindawi.com
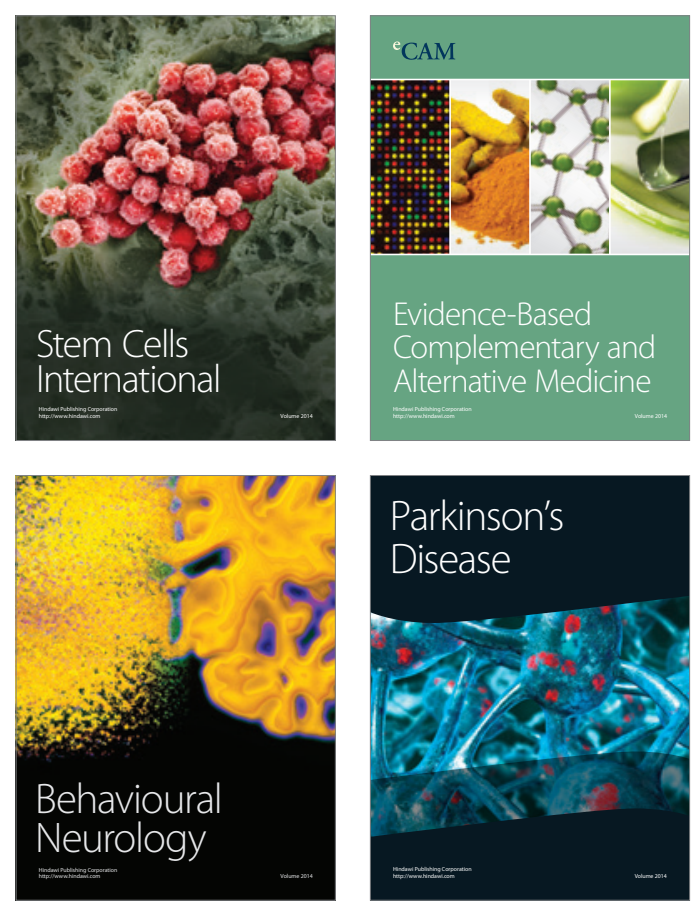

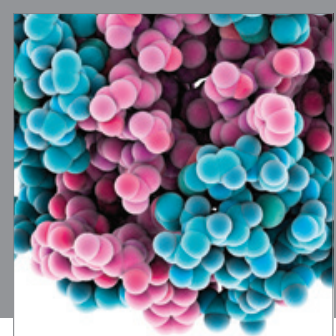

Journal of
Diabetes Research

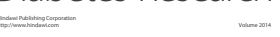

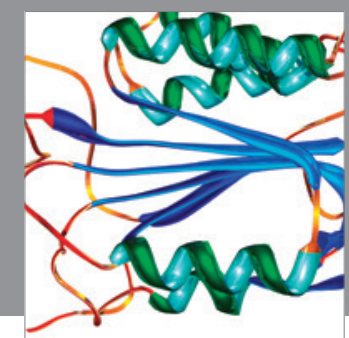

Disease Markers
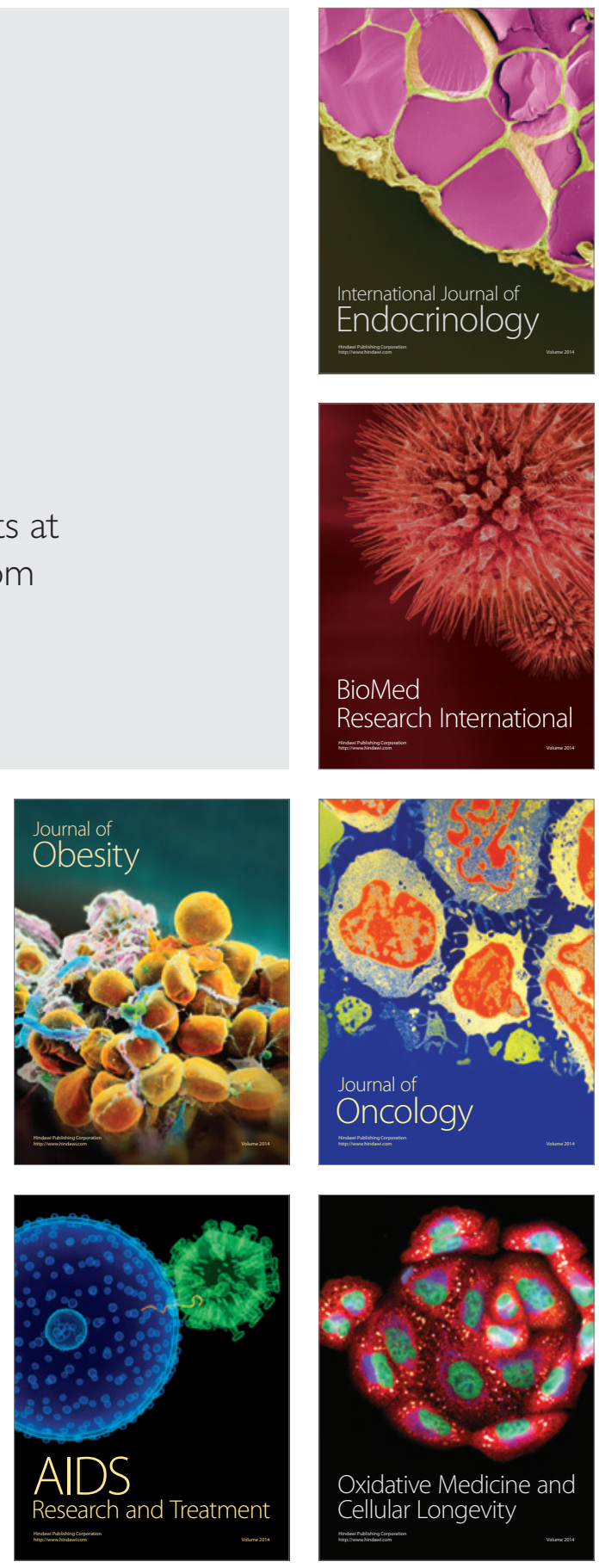